\title{
All Pay Auctions and Group Size: Grading on a Curve
}

\section{and other Applications*}

\author{
James Andreoni \\ Andy Brownback \\ University of California, San Diego University of Arkansas \\ and NBER
}

March 17, 2017

\begin{abstract}
We model contests with a fixed proportion of prizes, such as a grading curve, as all-pay auctions where higher effort weakly increases the likelihood of a prize. We find theoretical predictions for the heterogeneous effect auction size has on effort from high- and low-types. We test our predictions in a laboratory experiment that compares behavior in two-bidder, one-prize auctions with behavior in 20-bidder, 10-prize auctions. We find a statistically significant $11.8 \%$ increase in aggregate bidding when moving from the small to large auction. The impact is heterogeneous: as the auction size increases, low-types decrease effort but high-types increase effort. Additionally, the larger auction provides a stronger rank-correlation between effort and ability, awarding more prizes to the higher-skilled and improving the efficiency of prize allocation.
\end{abstract}

\footnotetext{
*Andreoni: Department of Economics, UCSD, La Jolla, CA 94093, andreoni@ucsd.edu. Brownback: Department of Economics, University of Arkansas, Fayetteville, AR 72701, abrownback@walton.uark.edu. Funding: Andreoni gratefully acknowledges the support of the National Science Foundation.
}

(C) 2017. This manuscript version is made available under the Elsevier user license http://www.elsevier.com/open-access/userlicense/1.0/ 


\section{Introduction}

We study the impact of changing group size in all-pay auctions with a fixed proportion of prizes. We derive theoretical predictions and confirm these with experimental evidence. While our findings are broadly applicable, to fix ideas and focus intuition we present the issues in terms of one of the most interesting applications of our result: grading on a curve. Students of heterogeneous skills choose how much effort to invest in a class in order to earn one of a fixed proportion of "A" grades. In this application, the skill level is the private value and the amount of effort invested in the course is the bid. The all-pay auction format suits the application since effort, the bid, is non-refundable. What makes the question of group size more interesting here is that the objectives of the educator as the auction designer may not be as simple as maximizing revenue, that is, total effort. They may also care about the distribution of effort among different students, or on accurately learning the relative skills of students, that is, the class ranking. Our analysis can help sort out the effects of class size on this array of possible objectives.

We show that as the enrollment of a course decreases, a given student becomes less sure of her percentile ranking in the course, and this increased uncertainty has asymmetric effects on those at the high and low ends of the population distribution of skills. For low skilled it means working harder is more likely to generate a top grade, while for the high skilled it means slacking off will be less likely to cost the student the coveted "A" grade. For the auction designer, the optimal class size will depend on the objectives. If the objective is to maximize total effort, then larger class sizes will produce more effort. If, however, the objective is to increase the effort of the lower skilled students, and thus improve their outcomes, then smaller class sizes will be optimal. Finally, if the objective is to accurately certify the ranking of students by the quality of their effort, then our experimental results suggest that larger class sizes are preferred.

While the application to classroom effort is natural and important, our results can be applied to many situations. Should an academic department set aside tenured slots for 
specific fields, such as a "macro" position and a "micro" position, or should it award the slots to the best candidates regardless of field? How should a large law firm structure it's awarding of partner to a cohort of associates? How does promotion based on seniority as well as effort compare to promotion based on effort alone? These and others are all interesting applications of our results.

We are, of course, not the first to examine the effect of the number of bidders in an all-pay auction. ${ }^{1}$ We distinguish our study from these by examining the effects of increasing the group size while maintaining the proportion of prizes, not simply the number of prizes. In addition, we focus not simply on the effects on auction profits, but our theory and our within-subject experimental design allow us to explore the heterogeneous impacts of group size for a continuum of types.

\section{Background}

The literature on all-pay auctions and contests dates back several decades ${ }^{2}$ and has been adapted to explore a wide variety of settings such as labor contracts (Lazear and Rosen, 1981), classroom grading (Becker and Rosen, 1992), and political lobbying (Hillman and Riley, 1989; Baye, Kovenock, and de Vries, 1993).

Experimental papers have studied changes in the structure of contests similar to ours. For example, Potters, de Vries, and van Winden (1998) and Davis and Reilly (1998) test bidding in Tullock contests under different structures. Other papers explore the effects of changes in the proportion of contestants awarded prizes (Barut, Kovenock, and Noussair, 2002; Gneezy

\footnotetext{
${ }^{1}$ Moldovanu and Sela $(2001,2006)$ theoretically explore the allocation of prizes and the optimal "architecture" of a contest for a fixed number of contestants, and Olszewski and Siegel (2013) look at how the number of bidders affects bids for a fixed number of prizes, rather than a fixed proportion of prizes as is done here. Experimentally, Harbring and Irlenbusch (2005) and Orrison, Schotter, and Weigelt (2004) test the effects of small changes in a contest's size on bidder behavior. Harbring and Irlenbusch (2005) employ homogeneous types and Orrison et al. (2004) only address heterogeneity among two types of players, one type advantaged by the addition of a constant to their output

${ }^{2}$ See Tullock (1967) and Krueger (1974). Baye, Kovenock, and de Vries (1996) provide the full characterization of the equilibria in the complete information all-pay auction, while Amann and Leininger (1996) and Krishna and Morgan (1997) expand the model to incorporate incomplete and possibly correlated information.
} 
and Smorodinsky, 2006; Lim, Matros, and Turocy, 2014; Harbring and Irlenbusch, 2005; Orrison et al., 2004). Still others have focused on the heterogeneity of bidding behavior in contests with a fixed size, noting a "bifurcation" between low- and high-ability types (Müller and Schotter, 2010; Noussair and Silver, 2006). Minor (2012) investigates this "coarse" behavior, where bidders choose between a small number of disparate strategies. ${ }^{3}$

Our investigation of the impact of changes in contest design on bidder heterogeneity, therefore, fills a natural and important gap in this literature. A focus on average effects of design changes has obscured the tension present between the interests of the high- and lowskilled contestants. We identify this tension theoretically, and then confirm its existence in our experimental results. In addition to the first test of the effects of a large-scale change in contest size, we employ a powerful design that identifies within-subject effects resulting from this change. By addressing this aspect of contest design, we hope to inform policy makers about the impact that changes in group size will have on people with different skill-levels when they are subject to relative evaluations.

\section{Theoretical Model}

Consider an independent private value all-pay auction. Values are drawn from a known distribution and represent the money earned when winning a prize. Bidders compete for a limited number of such prizes by simultaneously placing irreversible bids that must be paid regardless of the outcome of the auction. Prizes are awarded to the highest bidders, meaning an increase in bidding weakly increases the probability of receiving a prize. Uncertainty enters this model through an unknown draw of opponents. Bidders know the distribution from which all valuations are drawn, but do not know each other's realized values. ${ }^{4}$

\footnotetext{
${ }^{3}$ Dechenaux, Kovenock, and Sheremeta (2012) provide a complete review of the contest literature.

${ }^{4}$ Using a Tullock contest could have further integrated uncertainty into the model, though the two environments are qualitatively similar. Experimentally, the all-pay auction is simpler for subjects and we did not believe that the additional layer of complexity of the Tullock contest was worth the risk of confusion.
} 


\subsection{Basics of the Model}

Suppose a given auction has $N$ bidders. Call this the auction's size. Bidders compete for one of $P$ prizes with $P<N$. Each bidder independently draws a private value, $v_{i}$, with the commonly known cumulative distribution function, $F\left(v_{i}\right)$. These values can be thought of as a bidder's ability. ${ }^{5}$ Higher ability bidders gain more surplus from winning an auction than do lower ability bidders. This framework is isomorphic to an independent private cost of effort with the higher "ability" bidders having either higher valuations or lower costs of effort in the respective environments. ${ }^{6}$

A bidder competes for a prize by casting a bid, $b_{i}$, the cost of which is paid regardless of the outcome. Auctions are one-shot with simultaneous bids, so bidders cannot condition bids on the behavior of their competitors. Bidders with the $P$ highest bids receive one prize each. Let $\operatorname{Pr}_{N, P}\left(b_{i}\right)$ be the probability that bid $b_{i}$ will win a prize in an auction with $N$ participants and $P$ prizes.

Assume risk neutral, expected-utility maximizing bidders. ${ }^{7}$ A bidder's utility is then:

$$
\begin{aligned}
U\left(b_{i} ; v_{i}, N, P\right) & =\underset{N, P}{\operatorname{Pr}}\left(b_{i}\right)\left(v_{i}-b_{i}\right)+\left(1-\operatorname{Pr}_{N, P}\left(b_{i}\right)\right)\left(-b_{i}\right), \\
& =v_{i} \times \operatorname{Pr}_{N, P}\left(b_{i}\right)-b_{i}
\end{aligned}
$$

\subsection{Equilibrium Bidding}

Athey (2001) demonstrates the existence of a monotone Bayesian Nash equilibrium bidding function in pure-strategies. This equilibrium in pure strategies is possible as a result of the incomplete information about the valuations of other bidders. The precision of inference about the distribution of valuations among other bidders changes with the auction size. Equilibrium bidding, therefore, changes with the auction size as well. We will now construct

\footnotetext{
${ }^{5}$ For a detailed discussion of the differences between ability, value, and cost of effort, see Baik (1994).

${ }^{6}$ This isomorphism will not hold under preferences that do not maximize expected utility.

${ }^{7}$ In the appendix, we demonstrate that the qualitative predictions of the model generalize to risk aversion when risk aversion parameters are shared and common knowledge.
} 
equilibrium bidding functions for an arbitrary auction size.

Call the monotonic equilibrium bidding function $B\left(v_{i} ; N, P\right)$. This maps from the space of valuations onto the set of possible bids: $B: v_{i} \rightarrow b_{i}$, where $v_{i} \in[0,1]$ and $b_{i} \in[0,1] .^{8}$

Under monotonicity, there exists a function, $Z_{N, P}: v_{i} \rightarrow[0,1]$, that maps valuations to the equilibrium probabilities of winning a prize in an auction of size $N$ with $P$ prizes. Specifically, this function returns the probability that a valuation, $v_{i}$, is higher than at least $N-P$ of the $N-1$ other valuations in the auction. This is expressed as an order-statistic:

$$
Z_{N, P}\left(v_{i}\right)=\sum_{k=N-P}^{N-1}\left(\frac{(N-1) !}{(N-1-k) ! k !}\right) F\left(v_{i}\right)^{k}\left(1-F\left(v_{i}\right)\right)^{N-1-k}
$$

Recall, $F\left(v_{i}\right)$ is the cumulative distribution function for $v_{i}$.

It is straightforward to show that, as a well-defined, symmetric, strictly monotonic bidding function, $B: v_{i} \rightarrow \mathbb{R}^{+}$must also be continuous. ${ }^{9}$ Continuous, monotone functions are invertible implying that there exists a function, $B^{-1}\left(b_{i}\right)$, that maps bids cast onto the valuations implied by those bids. Denote this inverse function $V\left(b_{i}\right)$.

Incorporating $Z_{N, P}\left(V\left(b_{i}\right)\right)$ into the bidder's utility captures the incentive to deviate from equilibrium by assuming the bid associated with a different valuation. The first order condition of this utility function must be satisfied by any equilibrium bidding function. The modified utility and its first order condition are given by (3) and (4), respectively.

\footnotetext{
${ }^{8}$ Strict monotonicity follows naturally from the model. Parreiras and Rubinchik (2010) rule out weak monotonicity by contradiction: Suppose bidding were flat at a bid of $\hat{b}$ for a non-degenerate interval of valuations, then there would be a discontinuous jump in the probability of winning by bidding just above $\hat{b}$. This profitable deviation completes the contradiction by showing that it would never be optimal to bid $\hat{b}$. Strict monotonicity also satisfies intuition, as subjects likely understand that higher-valuation bidders will cast higher bids.

${ }^{9}$ Suppose a discontinuity were present at equilibrium. Bidders casting bids at the upper bound of the discontinuity would profit from decreasing their bid to just above the lower bound of the discontinuity. This would not change their probability of winning a prize, but would decrease their cost of bidding. This profitable deviation violates our assumption of equilibrium.
} 


$$
\begin{aligned}
U\left(b_{i} ; v_{i}\right)= & v_{i} \times \sum_{k=N-P}^{N-1}\left(\frac{(N-1) !}{(N-1-k) ! k !}\right) F\left(V\left(b_{i}\right)\right)^{k}\left(1-F\left(V\left(b_{i}\right)\right)\right)^{N-1-k}-b_{i} \\
\frac{1}{V^{\prime}\left(b_{i}\right)}= & v_{i} \times \sum_{k=N-P}^{N-1}\left\{\left(\frac{(N-1) !}{(N-1-k) ! k !}\right) \times\right. \\
& {\left[k \times f\left(V\left(b_{i}\right)\right) F\left(V\left(b_{i}\right)\right)^{k-1}\left(1-F\left(V\left(b_{i}\right)\right)\right)^{N-1-k}-\right.} \\
& \left.\left.(N-1-k) \times f\left(V\left(b_{i}\right)\right) F\left(V\left(b_{i}\right)\right)^{k}\left(1-F\left(V\left(b_{i}\right)\right)\right)^{N-2-k}\right]\right\}
\end{aligned}
$$

Since $V\left(b_{i}\right) \equiv B^{-1}\left(b_{i}\right)$, it follows that, $\frac{1}{V^{\prime}\left(b_{i}\right)}=B^{\prime}\left(v_{i}\right)$. Additionally, equilibrium requires that $Z_{N, P}\left(V\left(b_{i}\right)\right)=Z_{N, P}\left(v_{i}\right)$. We thus arrive at a first order differential equation from which we can solve the general form of the equilibrium bidding function,

$$
\begin{aligned}
& B^{\prime}\left(v_{i}\right)=v_{i} \times \sum_{k=N-P}^{N-1}\left\{\left(\frac{(N-1) !}{(N-1-k) ! k !}\right) \times\right. \\
& \left.\left[k \times f\left(v_{i}\right) F\left(v_{i}\right)^{k-1}\left(1-F\left(v_{i}\right)\right)^{N-1-k}-(N-1-k) \times f\left(v_{i}\right) F\left(v_{i}\right)^{k}\left(1-F\left(v_{i}\right)\right)^{N-2-k}\right]\right\} .
\end{aligned}
$$

We impose the initial condition $B(0)=0$ to solve this for given values for $N$ and $M .{ }^{10}$

\section{Experimental Model}

Before deriving predictions for this environment, it is important to address the selection of our experimental parameters. We believe our parameters accomplish a careful balance of salience for subjects, policy applicability, and ease of analysis and interpretation. To maximize salience, we chose a simple, linear prize structure with half of the participants receiving prizes. These choices may not perfectly reflect the classroom environment, but they capture the qualitative features of grading on the curve while allowing subjects to

\footnotetext{
${ }^{10}$ This initial condition is justified through dominance. Bids of $b_{i}<0$ are not possible, and, if $v_{i}=0$, bids of $b_{i}>0$ guarantee negative profits.
} 
easily understand the differences in treatments. ${ }^{11}$ We also chose nearly the largest change in the group size allowed by the size of the laboratory. ${ }^{12}$ This served to make changes in the treatment clear and provide a strong test of the theory by increasing the differences between the equilibrium effort functions. By identifying a sensitivity to group size, our results can make clear contributions to policy. Even if the sensitivity to group size is magnified by the stylized and artificially salient environment, we can confirm that predictable responses to changes in group size exist and should be accounted for. Finally, our parameter choices allow for a simplified analysis of our environment and interpretation of our data. This is particularly important for our subjects attempting to best respond to their environment.

Imposing our experimental parameters of $(N, P) \in\{(2,1),(20,10)\}$ and $v_{i} \sim U[0,1]$ on Equation 5, we get $^{13}$

$$
B_{2,1}\left(v_{i}\right)=\frac{v_{i}^{2}}{2}
$$

and

$$
\begin{aligned}
B_{20,10}\left(v_{i}\right)= & 83980 v_{i}^{11}-692835 v_{i}^{12}+2558160 v_{i}^{13}-5542680 v_{i}^{14} \\
& +7759752 v_{i}^{15}-\frac{14549535}{2} v_{i}^{16}+4564560 v_{i}^{17} \\
& -1847560 v_{i}^{18}+437580 v_{i}^{19}-46189 v_{i}^{20}
\end{aligned}
$$

Our subjects draw valuations uniformly from the set $\{\$ 0.01, \$ 0.02, \ldots, \$ 20.00\}$. Thus, we rescale the bidding functions to generate experimental predictions. Figure 1 plots the equilibrium bidding functions for the experimental parameters.

To understand the intuition behind the shapes of the bidding functions, consider the limit case for an all-pay auction with $P=\frac{N}{2}$ as $N \rightarrow \infty$. The infinitely large sample elimi-

\footnotetext{
${ }^{11}$ If, for example, we had used a non-linear prize structure, subjects would have required calculators to make their decisions.

${ }^{12}$ The UCSD EconLab can hold 24 subjects.

${ }^{13}$ Equations (6) and (7) allow us to check the second-order conditions for utility maximization computationally. We can see that the derivative of the expected utility function is positive for any possible alternate bid, $\underline{\mathrm{b}}<B\left(v_{i}\right)$, and negative for any alternate bid, $\bar{b}>B\left(v_{i}\right)$. Thus, our bidding function maximizes the expected utility function. For a general proof of this, see Moldovanu and Sela (2001).
} 


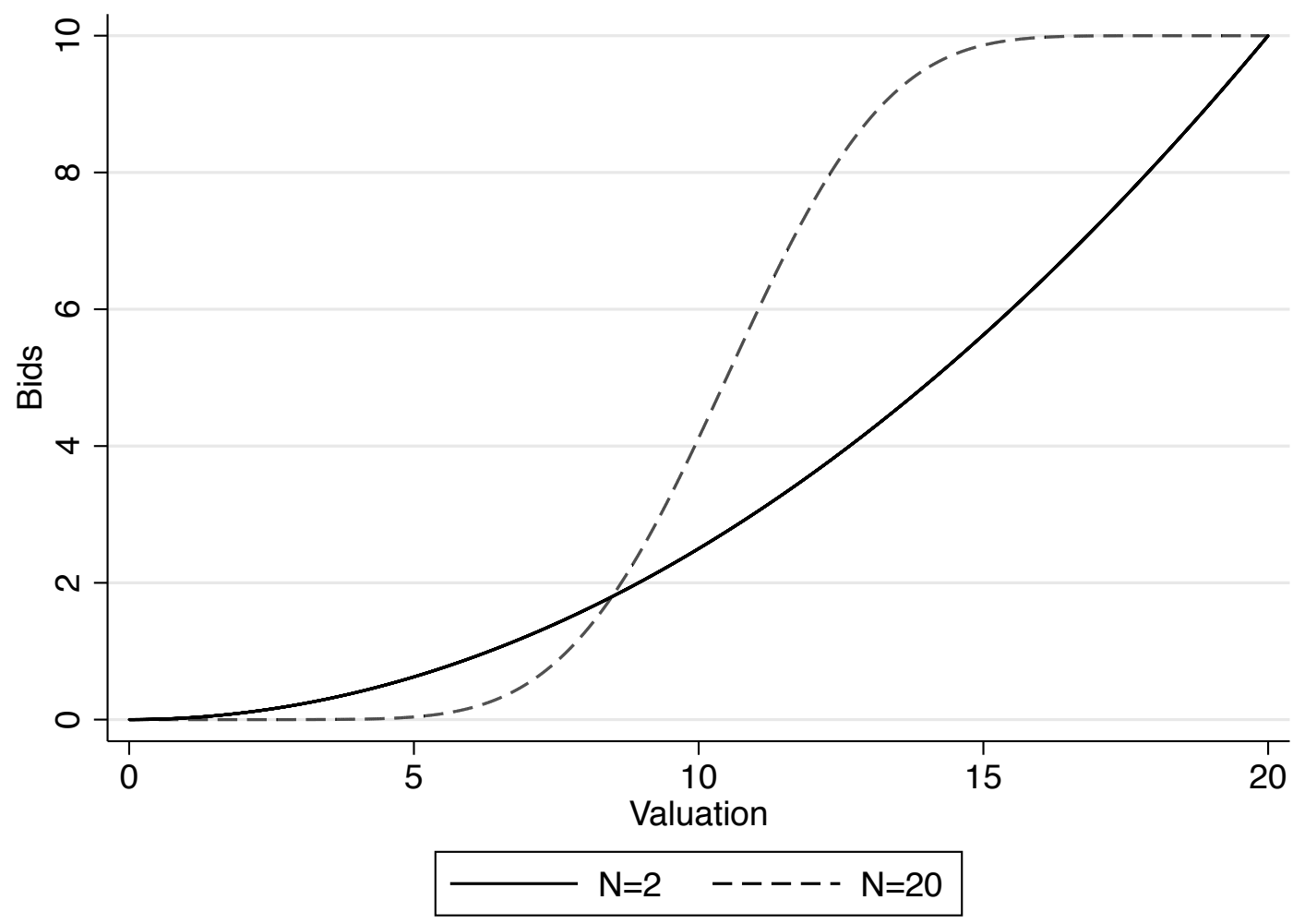

Figure 1: Equilibrium Bidding Functions

nates uncertainty about the distribution of opponents' valuations, and the bidding function approaches a step function. Here, only the top half of bidders receive prizes, so any bidder below the median (i.e. $v_{i}<\$ 10$ ) bids $b_{i}=\$ 0$, while bidders above the median (i.e. $v_{i}>\$ 10$ ) bid $\tilde{b}$, a bid that makes the marginal bidder indifferent between winning the auction with a bid of $\tilde{b}$ and losing the auction with a bid of zero. ${ }^{14}$ In the case of $P=\frac{N}{2}$, the marginal bidder has $v_{i}=\$ 10$ and the bid that makes the marginal bidder indifferent is $\tilde{b}=\$ 10$.

Extending this intuition to our experiment, we can see how a change in the size of the auction affects the equilibrium bidding functions. The large auction in our experiment is ten times the size of the small auction, drawing its distribution of valuations closer to the underlying probability distribution than the small auction. For this reason, equilibrium bids

\footnotetext{
${ }^{14}$ At equilibrium in the limit case, bidders have probability measure zero. Thus, the rules must change to reflect the nature of the contest. Now, prizes will be awarded to bidders in descending order of their bids until half of the bidders have received prizes. Otherwise, there are profitable deviations from equilibrium.
} 
in the 20-Person Auction more closely reflect bidding in the limit case.

Now, consider a bidder with $v_{i} \geq \$ 10$ choosing how far below the limit-case bid of $b_{i}=\$ 10$ he wants to bid in each auction. The marginal benefit of lowering a bid is constant across auctions. Bids are paid with certainty, so foregone bids are recovered with certainty. The marginal cost of lowering a bid - paid by reducing the probability of winning a prize — varies across auctions. This decrease in probability is greater in the large auction than in the small auction, thus bids cast by high-valuation bidders are larger in the large auction.

Consider the same marginal analysis for a bidder with $v_{i}<\$ 10$ choosing how far above the limit-case bid of $b_{i}=\$ 0$ he wants to bid in each auction. The marginal cost of increasing bids is constant, while the marginal benefit of increasing bids is probabilistic. At sufficiently low valuations, the marginal increases in the probability of winning a prize are higher in the small auction, causing bids in the small auction to rise above bids in the large auction. ${ }^{15}$

Our experimental design collects bids from both auction sizes. Thus, we will test the model's ability to predict differences in bids across the two auctions. Equation 8 begins to generate predictions about bidding differences by subtracting the predicted bidding functions. This difference is captured graphically in Figure 2.

$$
\begin{aligned}
B_{2,1}\left(v_{i}\right)- & B_{20,10}\left(v_{i}\right)=\frac{v_{i}^{2}}{2}-83980 v_{i}^{11}+692835 v_{i}^{12}-2558160 v_{i}^{13} \\
& +5542680 v_{i}^{14}-7759752 v_{i}^{15}+\frac{14549535}{2} v_{i}^{16}-4564560 v_{i}^{17} \\
& +1847560 v_{i}^{18}-437580 v_{i}^{19}+46189 v_{i}^{20}
\end{aligned}
$$

There are two features of this predicted difference that we will specifically test. The

\footnotetext{
${ }^{15}$ We show in the appendix that (surprisingly) the equilibrium is not strongly affected by imposing riskaversion on the bidders' utilities. This is because bidding is driven by changes in probability-which is unaffected by risk aversion, not changes in surplus - which is affected by risk aversion. See the appendix for a graph of the equilibrium bidding functions under common risk aversion parameters. We also include a graph of the equilibrium under a common joy-of-winning value in the appendix. Trivially, this added degree of freedom improves the model's fit. We do not include this specification in the discussion, because it provides identical predictions about the effect of changing the auction size.
} 


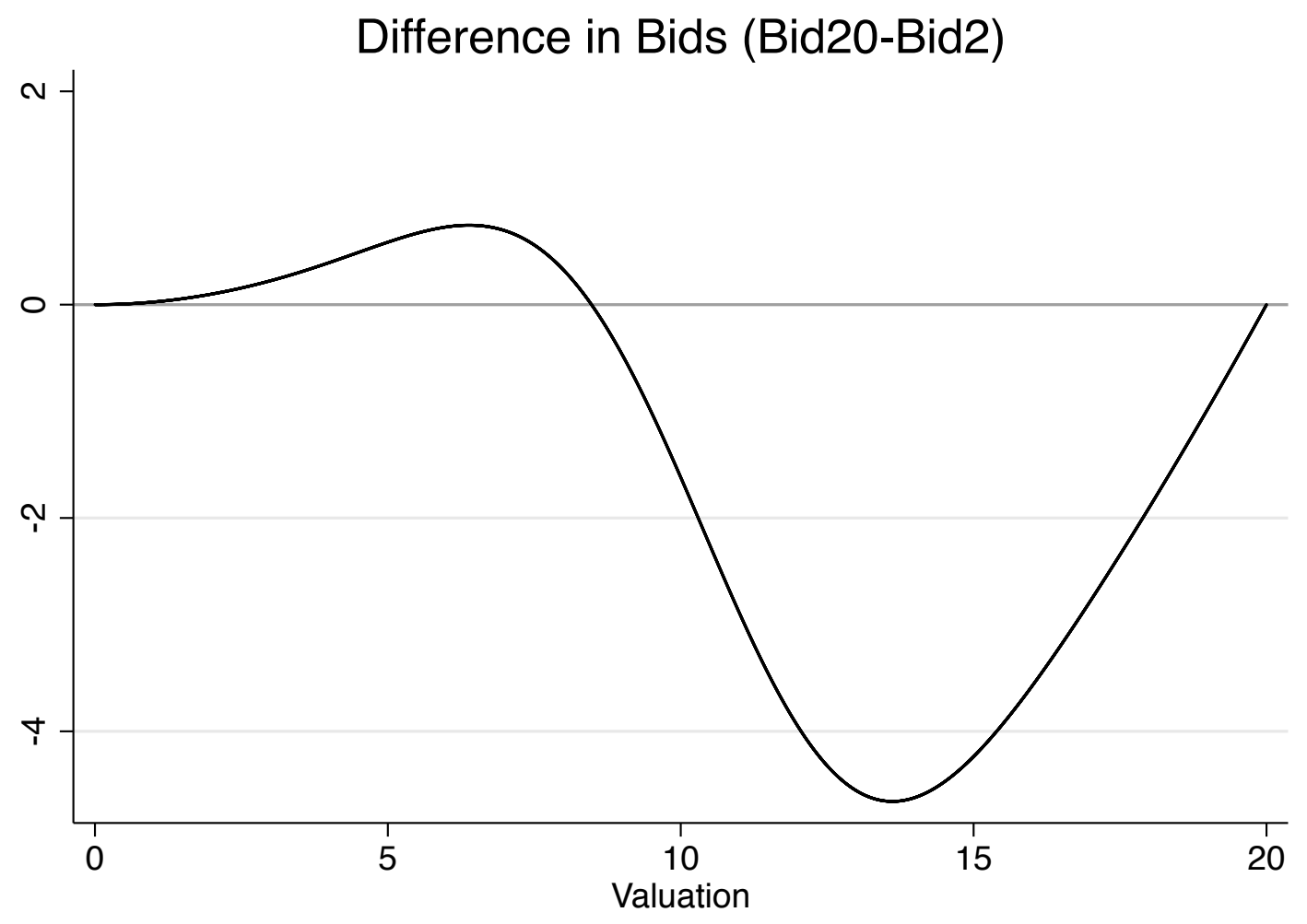

Figure 2: Predicted Difference in Equilibrium Bidding

detailed proofs of each prediction can be found in the appendix.

\section{Prediction 1: Aggregate bidding increases in the size of the auction}

We begin by testing for differences in aggregate bidding. This is visible through the relative size of the positive and negative area under the difference curve. Specifically, the area under the predicted bidding function for the 2-person auction is $\int_{v=0}^{20} B_{2,1}(v)=\$ 66.67$, while the area under the predicted bidding function for the 20-person auction is $\int_{v=0}^{20} B_{20,10}(v)=\$ 95.25$. Since we will have exactly 20 bidders each round drawing values uniformly from $v_{i}=\$ 0$ to $v_{i}=\$ 20$, the area under each curve represents the expected revenue from all bids cast in each auction size. ${ }^{16}$ In absolute terms, we expect that the larger auctions capture $\$ 28.58$ more revenue per period or 1.43 times as much revenue. The prediction that revenues increase

\footnotetext{
${ }^{16}$ The expected revenue from any one 2-person auction is proportionally smaller: $\$ 6.67$
} 
as the size of the auction grows - holding fixed the proportion of winners - is proven in Moldovanu and Sela (2006). ${ }^{17}$

\section{Prediction 2: Predicted bids from the larger auction cross predicted bids from the smaller auction from below exactly once}

The second feature of this predicted difference we will test is the single-crossing property where predicted bids in the 20-person auction meet those of the 2-person auction. We derive this prediction by setting Equation 8 equal to zero and solving for $v_{i}$. At $v_{i} \approx 8.477$, bids in the two auctions are equal with $B_{2,1}(8.477)=1.796=B_{20,10}(v)$. We predict that bids in the larger auction cross from below. For $v_{i}<8.477$, predicted bids in the 2-person auction exceed those of the 20-person auction. Conversely, for $v_{i}>8.477$, predicted bids in the 20-person auction exceed those of the 2-person auction. Following the framework of Moldovanu and Sela (2006), we prove this single-crossing property for generic auction sizes in the appendix.

\section{$5 \quad$ Experimental Hypotheses}

The model provides strong predictions about how bidders will behave in each auction. A strict test of the model's fit compares observed bidding levels to the Bayes-Nash equilibrium predictions shown in Figure 1. Our paired auction design, which compares bidding in different auction sizes, opens up a novel second channel through which we can evaluate the model - its accuracy in predicting changes in bidding.

In addition to these specific tests, we consider three general predictions of the model. We state these general predictions in terms of a teacher's objectives and use them to highlight tensions between different objectives a mechanism designer may have. In the event that the equilibrium prediction holds, the general predictions will follow. But, even if the precise equi-

\footnotetext{
${ }^{17}$ As part of their proof of Proposition 2, they show that the expected bid in an isomorphic contest with $N$ bidders and $p$ winners is proportional to the order statistic of the $p+1$-th highest ability bidder. For $p=N / 2$, as $N \rightarrow \infty$, this order-statistic monotonically increases towards the median of the distribution of abilities.
} 
librium prediction is rejected by statistical tests, tests of the more general effects of contest size will still be informative for the policy debate about the merits of different contest sizes. Thus, we test the equilibrium predictions and the qualitative predictions independently.

Given the complexity of the equilibrium bidding functions, strict hypotheses about equilibrium bidding levels are rather restrictive. Even with experience, the complexity of the bidding functions and the lack of clear heuristics makes a tight fit between the data and the theory unlikely. Our design allows us to consider a less restrictive test of the changes in bidding between auctions. These tests of equilibrium behavior will form a starting point for our hypotheses before we move on to the more general predictions identified below.

\subsection{Qualitative Predictions: The Designer's Objectives}

The objectives we consider are designed around encouraging effort from students, since educators generally pursue classroom policies that increase rather than decrease effort. While auction bids accrue solely to the designer, it need not be the case that the designer alone benefits from effort. Our results hold implications for any environment where the rewards for effort are more salient - for example, psychologically or materially - to the designer than to the agents. For instance, exerting effort may feel like a wasteful action to students in principles of economics, but educators believe that there are benefits to this effort that are not yet clear to the students.

One typically thinks of an auction designer as having the unique objective of maximizing revenues but there may be other objectives competing for attention in the minds of policymakers applying these insights to education. We consider three such potential objectives. While we will only develop clear predictions for two of them, our experiment cleanly tests all three. 


\section{Objective 1: Maximize aggregate effort from students.}

Holding fixed the proportion of prizes, the model predicts that aggregate bidding increases in the size of the auction. These increases reduce the uncertainty about the distribution of valuations among other bidders. With tighter predictions about the distribution of valuations a bidder faces, high-valuation bidders face greater probabilistic costs associated with casting low bids. Increased bidding from high-valuation bidders more than offsets decreased bidding from low-valuation bidders.

\section{Objective 2: Differentially weight effort from low-and high-ability students.}

It is reasonable to expect, especially in the arena of education, that policy makers may not simply wish to maximize total effort, but might care from what type of students that effort comes. A policy may be designed to help the best students "realize their full potential" or help prevent the most challenged students from being "left behind."

As discussed under Objective 1, we predict that high-valuation bidders will cast higher bids in the larger auction. For low-valuation bidders, however, the decreased uncertainty about the distribution of bidders in the larger auction drives down bidding. Therefore, we expect to see higher bids in the small auction for low-valuation bidders. It follows that policies designed to differentially favor effort from low-ability students would promote smaller class sizes, while policies designed to favor effort from high-ability students would promote larger classes.

Figure 1 plots the model's specific prediction that the bidding functions intersect at $v_{i}=\$ 8.48$. We test this prediction in two ways. First, we compare bids in the small auction to those from the large auction for bidders with valuations on either side of $v_{i}=\$ 8.48$. Second, we estimate the point where observed bids in the large auction begin to dominate bids in the small auction and compare it to the model's prediction of $v_{i}=\$ 8.48$. 


\section{Objective 3: Accurately order student ability based on effort.}

A mechanism designer may want to use the bids cast to infer the ranking of valuations. For instance, a teacher may want to use her students' test scores to estimate the relative intelligence of her students. Deriving predictions in this domain from a symmetric equilibrium model provides little traction because symmetric bidding functions produce a one-to-one, monotonic matching of bids to valuations. As a result, relative bidding perfectly reflects relative valuations.

Since the ability to rank valuations based on bids holds important policy-relevance and our design provides a clean test of this relative ability, we will explore this objective empirically. In particular, we will empirically explore the role of changes in the size of the auction on 1) the overall ordering of bids, 2$)$ the ordering of bids within low-valuation $\left(v_{i}<\$ 10\right)$ and high-valuation $\left(v_{i}>\$ 10\right)$ bidders, and 3) the ordering of bids between low-valuation and high-valuation bidders - comparisons where valuations are on opposite sides of $v_{i}=\$ 10$.

\section{$6 \quad$ Experimental Procedures}

To test the sensitivity of effort to a change in the size of a contest, we employ an independent private value all-pay auction with multiple prizes. We use a paired bidding design similar to Kagel and Levin (1993) and Andreoni, Che, and Kim (2007) in which we elicit two bids from each bidder in each round - one bid for the large auction and one for the small auction. This is a powerful design that allows us to pair data perfectly and test our hypotheses about the difference in bidding within-subject while holding valuation constant.

\subsection{Recruitment and Participation}

60 undergraduate students from the University of California, San Diego (UCSD) participated in our experiment. The experiment was conducted in 3 sessions in February of 2013 in the EconLab at UCSD. Each session required exactly 20 subjects and lasted approximately 90 
minutes. All subjects received a $\$ 20$ participation payment. Subjects took home between $\$ 15$ and $\$ 45$ after adding any gains or deducting any losses.

\subsection{Instructions}

We first read the instructions aloud to all subjects and then administered a quiz to test their comprehension of the auction formats and the payoffs from different outcomes. ${ }^{18}$

Our instructions made clear the means by which we awarded prizes and the payoffs conditional on receiving or not receiving a prize. We carried out the entire experiment on computers using the Z-Tree Economics Software (Fischbacher, 2007). Key instructions remained posted at the top of every decision screen. This feature helped us remind subjects that bids would be deducted from their winnings regardless of the outcome of the auction, that their final payment for the experiment would be determined by one auction selected at random, and that they would see two auctions for each valuation they drew-the 2-Person Auction, then the 20-Person Auction. For all auctions, subjects were reminded of the number of opponents they faced and the number of prizes available.

\subsection{Auction Design}

Every round, subjects received valuations drawn uniformly in $\$ 0.01$ increments between $\$ .01$ and $\$ 20.00$. That is, $v_{i} \sim U[\$ .01, \$ 20.00]$. Using this valuation, subjects participated in both a "2-Person Auction," for which they were randomly and anonymously paired, and a "20-Person Auction," which consisted of all participants in the session. ${ }^{19}$

Subjects cast bids for both auctions in every round. After all subjects cast bids, we revealed all winning and losing bids cast by all bidders in all auctions that round. Each

\footnotetext{
${ }^{18}$ The instructions and quiz can be found in the appendix.

${ }^{19}$ This structure gives us the largest change from one size of contest to the other. Since the 20-Person Auction features a stable cohort, issues with collusion could arise. If this were the case, bids in the 20-Person Auction would decrease with experience. We find that bids do drop in later rounds, though bids drop more in the smaller auction than the larger auction, contradicting the collusion hypothesis. To the extent that collusion remains a possibility, it suggests bidding should decrease in the larger auction, which biases us away from our hypotheses.
} 
subject was also informed of his own payoffs from both auctions that round. All bids were cast without knowledge of opponents' bids or valuations, so we consider them simultaneous bids under incomplete information. No communication was allowed, and we never revealed the valuations associated with any bids by other subjects.

Subjects then drew new valuations and new partners for the 2-Person Auction before repeating the auction round. For each new valuation they drew, they cast bids in the 2and 20-Person Auctions. Subjects in session 1 repeated the auction rounds 20 times, while subjects in sessions 2 and 3 repeated them 15 times. To be conservative and uniform in our analysis, we restrict our sample to the first 15 rounds of each session. ${ }^{20}$ At the end of the experiment, one auction in one round was selected at random to determine each subject's payments.

After completing the auction rounds, we used a discretization of the method developed in Andreoni and Harbaugh (2016) to elicit subjects' risk preferences. ${ }^{21}$ We will use our estimates of risk preference and demographic data as controls in our analysis.

\section{$7 \quad$ Results}

Subjects drew valuations and cast bids in two different auctions for 15 rounds. From this, we collected a total of 1800 different bids for 900 valuations. 12 of these bids were strictly dominated - the bid exceeding the valuation of the bidder - and guaranteed the bidder a negative payoff. ${ }^{22}$ Dominated bids were evenly distributed across periods and auction sizes. We omit only one of these dominated bids, a $\$ 99$ bid in the final 20-Person Auction of session 3. This bidder had a valuation of $\$ 0.38$, guaranteeing a loss of $-\$ 98.62$ from this auction. Since we cannot fathom that this choice represents true preferences, we omit it in order to

\footnotetext{
${ }^{20}$ See the appendix for the analysis including all 20 rounds of session 1 . Our results increase in magnitude and significance. Our initial experimental design called for 20 rounds in 90 minutes. During the first session we discovered that this time allowed for only 15 rounds, which is how we completed the experiment.

${ }^{21}$ This elicitation can be found in the appendix.

${ }^{22}$ Overbidding in this way has been documented in several studies using common-value all-pay auctions (Gneezy and Smorodinsky, 2006, for example), but does not represent a large fraction of bids in independent private value all-pay auctions (Noussair and Silver, 2006).
} 
improve the accuracy of our point estimates, although none of our significant results are rendered insignificant by its inclusion.

Figure 3 compares the aggregate patterns of bidding across different valuations to their predictions. We split the data by valuation into 10 equally-sized bins. Adjacent dots show the mean and $95 \%$ confidence intervals of the bids in each auction size. Figure 3 shows that all bids are near-zero for low valuations regardless of auction size. The larger auction begins to dominate over middle-valuations, as predicted. For high valuations, bids are close to the equilibrium predictions with little difference between the two auction sizes. ${ }^{23}$

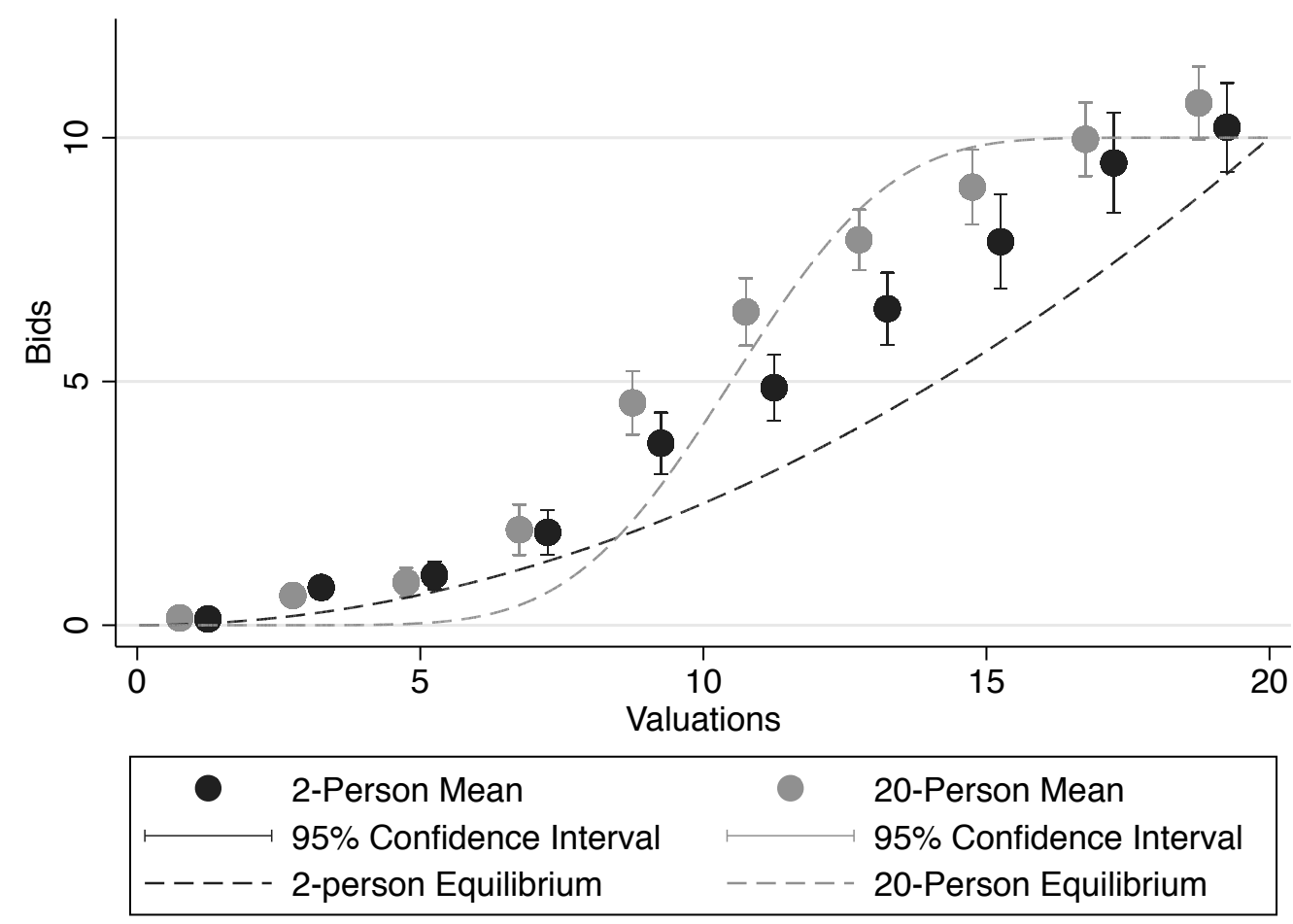

Figure 3: Mean Bidding across Valuations

To leverage our paired design, we evaluate the experimental hypotheses based on their predictions about the difference between the 2- and 20-Person Auction bids at a given valuation. Figure 4 compares the observed differences in bids to the model's predicted difference.

\footnotetext{
${ }^{23}$ For a finer resolution display of subject bidding, we separate individual bids by auction size and session and plot them against the bidder's valuation. We include these graphs in the appendix rather than here, since the volume of bids - 300 per graph - makes the graphs difficult to interpret parsimoniously.
} 
The observed differences are averaged within the same 10 equally-sized bins as before.

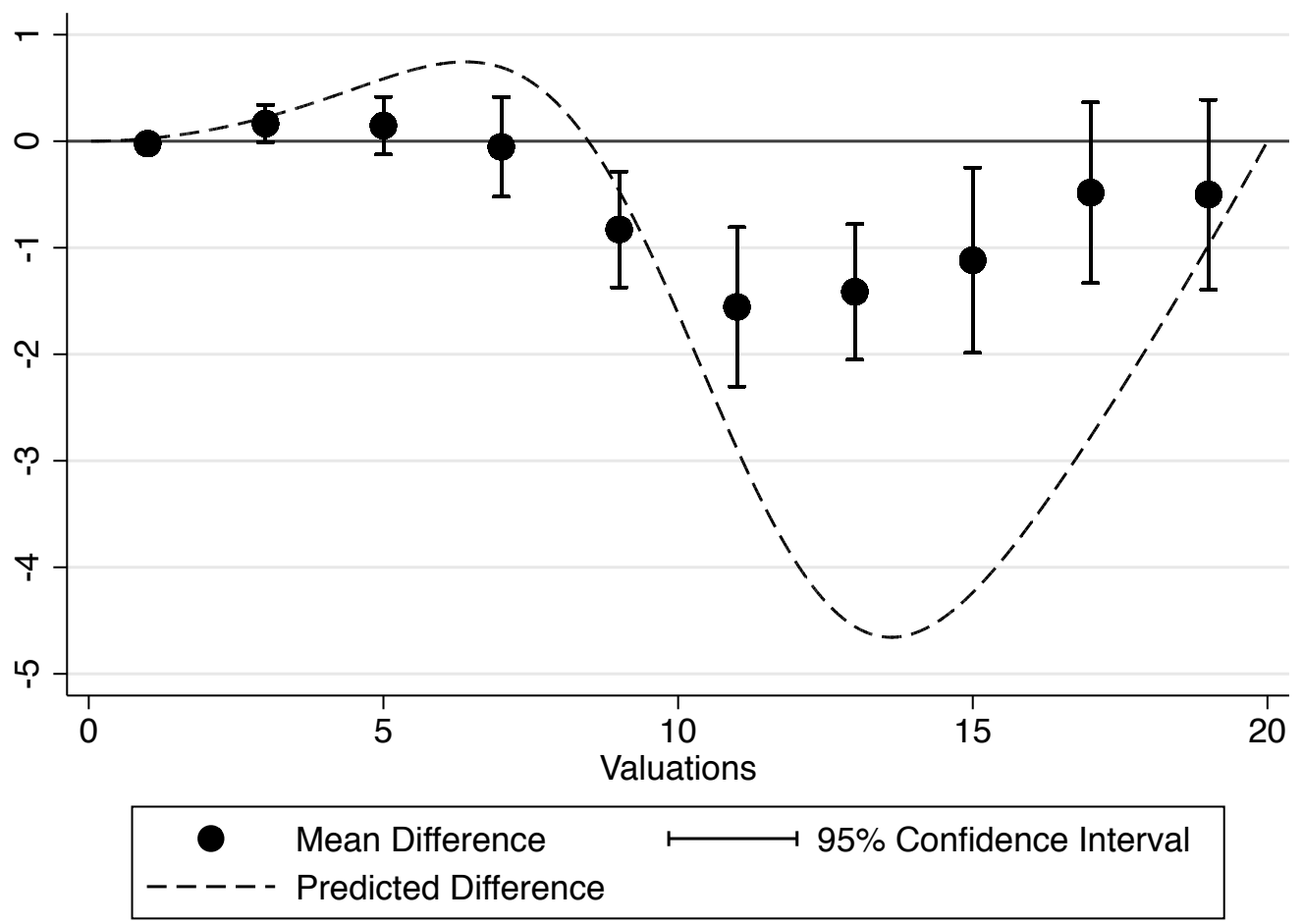

Figure 4: Bidding Differences: 2-Person Auction Bid minus 20-Person Auction Bid

\subsection{Nash equilibrium predictions}

We begin with our strict test of equilibrium bidding.

Statistical tests reveal that there are systematic deviations between individual bids and their equilibrium predictions both in the 2-Person Auction $(t=7.00, p<0.001, n=900)$ and the 20-Person Auction $(t=4.73, p<0.001, n=893)$. Comparing differences in bidding with the difference in the equilibrium predictions yields a similar rejection of the theoretical predictions $(t=4.87, p<0.001, n=899) .{ }^{24}$

Of course, one should not be surprised that in this unique environment that a model

\footnotetext{
${ }^{24}$ These and all other within-subject tests use standard errors clustered at the subject level. Session level clusters are not advised. With only 3 clusters, we introduce the potential for bias (Bertrand, Duflo, and Mullainathan (2004)). While there may be cause to believe that session characteristics influence bidding levels, our unit of analysis is within-subject, thus clustering at the session level is only justified if there is reason to believe that session characteristics somehow drive bidding differences within an individual bidder.
} 
with complex and precise predictions fails these statistical tests. As the literature on auction experiments reveals, the theory often provides a good benchmark but seldom predicts precise outcomes. Indeed, Figure 4 makes it clear that the differences between bids in the 2- and 20-Person Auctions evolve in a way that is qualitatively similar to the model's predictions. Therefore, the question for the following objectives becomes whether, despite the lack of a precise fit, the qualitative predictions and intuitions gleaned from theory are useful in predicting behavior.

\subsection{Objective 1: Maximize aggregate bidding.}

In 34 of the 45 rounds, revenues were greater in the larger auction, consistent with our theory. Using each round as an observation, we perform a paired t-test on the difference in total revenue between auctions and find that the larger auctions generate significantly more revenue $(t=4.92, p<.001, n=45)$. Our paired design allows us to test this hypothesis at a the individual level and perform a paired t-test matching each bid in the large auction with its counterpart in the small auction. We find a mean increase in bidding of $\$ 0.56$ when moving from the small to the large auction $(t=2.85, p=.006, n=899)$. While this difference is significantly different from zero, it is also significantly smaller than the predicted average difference of $\$ 1.43(t=4.87, p \approx .000, n=899)$.

We also derived predictions about the proportional change in bidding across auction sizes. The model predicts that the average bid in the 20-person auction is 1.43 times as large as the average bid in the 2-person auction. We observe that the average bid in the 20-person auction is only 1.11 times as large as its counterpart in the 2-person auction. 


\subsection{Objective 2: Differentially weight effort from low- and high- ability students.}

The model predicts that bids in the small auction will dominate bids in the large auction for low valuations, while bids in the large auction will dominate for high valuations. Our specific theoretical prediction places this crossover at $v_{i}=\$ 8.48$.

Figure 4 confirms this prediction of relative dominance for high-valuation bidders, but not low-valuation bidders. The behavior of low-valuation bidders appears to be invariant to auction size, while high-valuation bidders seem to show sensitivity to the auction size.

We test this prediction in two ways. First, we estimate a fitted crossover point where bids in the large auction begin to dominate bids in the small auction. To estimate the valuation at which bids in the large auction begin to dominate those of the small auction, we use a locally-linear polynomial smoothing function to fit the difference in bids across valuations. We plot this function in Figure 5 , which shows the fitted crossover point at $v_{i} \approx \$ 6.71$. While this diverges from the precise theoretical prediction about the location of the single-crossing point, it confirms the single-crossing nature of the bidding functions with bids in the small auction dominating at first, before bids in the large auction begin to dominate.

The second way we test predictions about relative dominance is by comparing relative bidding levels on either side of the theoretical and fitted crossover points. We use the theoretical crossover point of $v_{i}=\$ 8.48$ to split our data into two bins, LowerBin and UpperBin, and test our theory's predictions about relative bidding in each bin. To best exploit our paired data, our dependent variable will be the bid in the small auction minus the bid in the large auction. Our theory predicts that the difference will be positive until $v_{i}=\$ 8.48$ and negative afterwards. In column 1, we regress this difference onto Lower Bin and UpperBin with standard errors clustered at the subject level. In column 2, we repeat this regression with controls for the elicited risk preferences. ${ }^{25}$ The results can be seen in

\footnotetext{
${ }^{25}$ Risk aversion does not have a clear prediction, since it affects high-valuation and low-valuation bidders differently. Thus, we interact these controls with the bins for different valuations.
} 


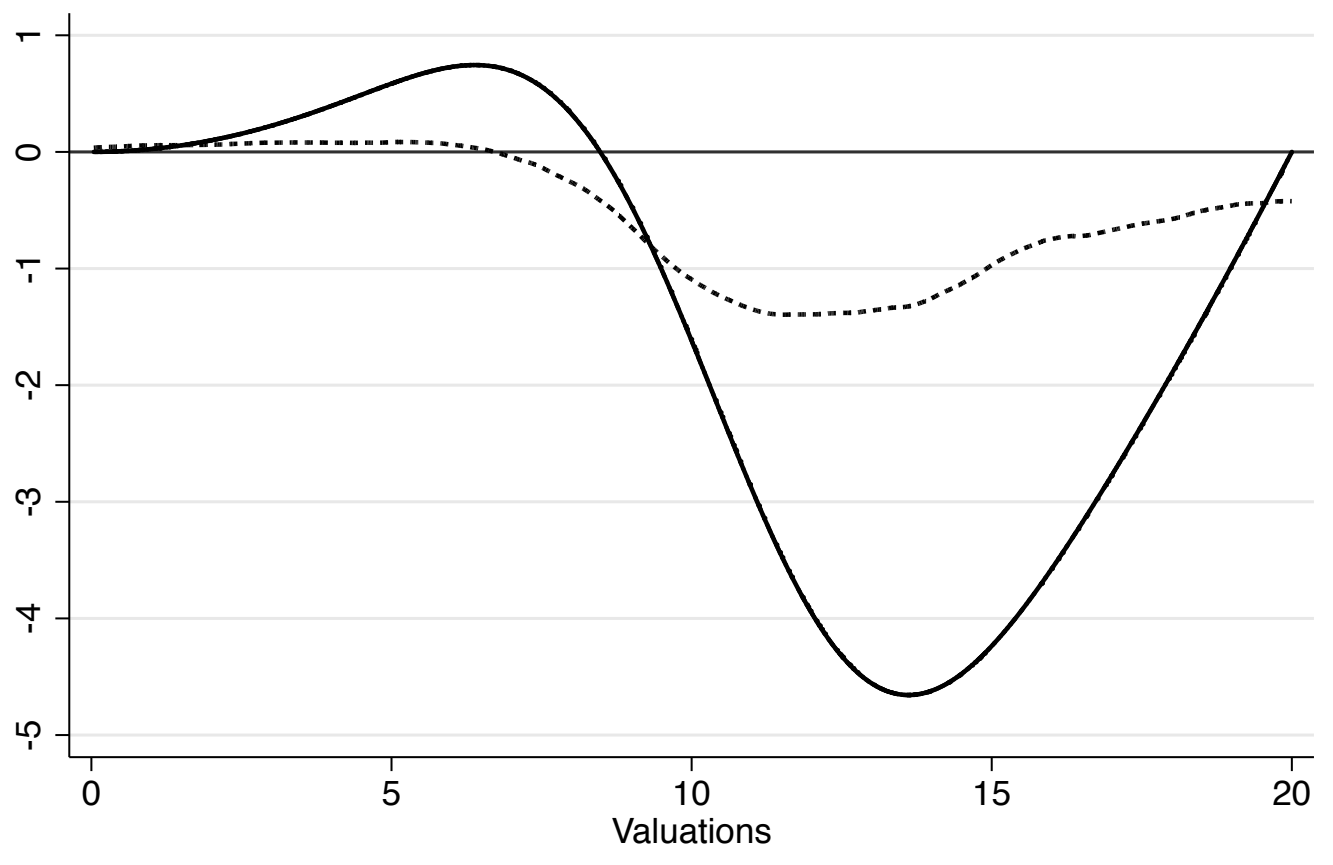

Equilibrium Difference ...-...-. Fitted Prediction

Figure 5: Predicted Difference in Bids: 2-Person Auction Bid minus 20-Person Auction Bid the left-hand side of Table 1. In column 3, we restrict the sample to experienced bidders.

We repeat this analysis with the fitted crossover point, generating new dummy variables, Lower FitBin and UpperFitBin, for valuations below the fitted crossover point, $v_{i}=\$ 6.71$. The results are found on the right-hand side of Table 1.

The difference in bids in the upper bin is large in magnitude and highly statistically significant. This difference in bids is also statistically distinguishable from the same difference in the lower bin. However, the difference in bids in the lower bin is not statistically distinguishable from zero. Recall that the predicted difference in bids is small over lower valuations, so it is not surprising that the observed differences are not statistically significant. For valuations just above the median, however, we predict large differences between bids cast in the large and small auction. This separation is clearly displayed in statistical tests and graphical analysis. Experience appears to favor the large auction, with the difference in bids between the 2- and 20-Person Auctions growing in the later rounds. 
Table 1: The difference in bids (2-Person Auction bid - 20-Person Auction bid)

\begin{tabular}{|c|c|c|c|c|c|c|}
\hline \multirow[b]{2}{*}{ Periods: } & \multicolumn{3}{|c|}{ Predicted Cutoff: $\$ 8.48$} & \multicolumn{3}{|c|}{ Fitted Cutoff: $\$ 6.71$} \\
\hline & $1-15$ & $1-15$ & $9-15$ & $1-15$ & $1-15$ & $9-15$ \\
\hline $\begin{array}{l}\text { LowerBin=1 } \\
\text { if } V_{i} \leq \$ 8.48\end{array}$ & $\begin{array}{c}0.0816 \\
(0.10)\end{array}$ & $\begin{array}{l}0.0857 \\
(0.09)\end{array}$ & $\begin{array}{c}-0.0920 \\
(0.14)\end{array}$ & & & \\
\hline $\begin{array}{l}\text { UpperBin=1 } \\
\text { if } V_{i}>\$ 8.48\end{array}$ & $\begin{array}{c}-0.997^{* * *} \\
(0.31)\end{array}$ & $\begin{array}{c}-0.957^{* * *} \\
(0.29)\end{array}$ & $\begin{array}{c}-1.151^{* * *} \\
(0.40)\end{array}$ & & & \\
\hline $\begin{array}{l}\text { LowerFitBin=1 } \\
\text { if } V_{i} \leq \$ 6.71\end{array}$ & & & & $\begin{array}{c}0.0598 \\
(0.08)\end{array}$ & $\begin{array}{c}0.0576 \\
(0.08)\end{array}$ & $\begin{array}{c}-0.0516 \\
(0.09)\end{array}$ \\
\hline $\begin{array}{l}\text { UpperFitBin=1 } \\
\text { if } V_{i}>\$ 6.71\end{array}$ & & & & $\begin{array}{c}-0.849^{* * *} \\
(0.28)\end{array}$ & $\begin{array}{c}-0.835^{* * *} \\
(0.26)\end{array}$ & $\begin{array}{c}-1.081^{* * *} \\
(0.37)\end{array}$ \\
\hline R.A. Controls & No & Yes & Yes & No & Yes & Yes \\
\hline $\mathrm{N}$ & 899 & 899 & 419 & 899 & 899 & 419 \\
\hline
\end{tabular}

\subsection{Objective 3: Accurately order bidders based on their bids.}

We test which auction best accomplishes Objective 3 with Kendall's (1938) tau rank correlation coefficient (Hereafter, K-T). The K-T coefficient measures the ratio of concordant pairs to discordant pairs. A pair of bids is concordant if the ranking of the two bids is consistent with the ranking of the valuations of the bidders $\left(b_{i}<b_{j} \Longleftrightarrow v_{i}<v_{j}\right)$, while a pair of bids is discordant if it is inconsistent with the rankings of the bidders' valuations $\left(b_{i}>b_{j} \Longleftrightarrow v_{i}<v_{j}\right) .^{26}$

The K-T coefficients and their significance tests for the pooled data are reported in the first two rows of Table 2 . In row 3, we generate one $\mathrm{K}-\mathrm{T}$ coefficient for each auction in each period before running a paired t-test of the two auctions from a given period. ${ }^{27}$

\footnotetext{
${ }^{26}$ Mathematically, the K-T coefficient is $K=\frac{C-D}{\left(\frac{N \times(N-1)}{2}\right)}$, where $N$ is the total number of bids cast. We can also correct for ties in bids or valuations according to Kendall (1970). The signs and significance of our results are maintained or increased with this correction. We chose Kendall's tau over a possibly more recognizable test of rank-correlation, the Spearman (1904) coefficient, because Spearman's coefficient is more heavily influenced by outliers, biasing our results in the direction of the large auction, and because Kendall's tau has a more straightforward interpretation. Our results have the same signs and larger magnitudes using Spearman's coefficient.

${ }^{27}$ Given that we have 45 pairs of K-T statistics, we invoke the Central Limit Theorem and perform a
} 
Table 2: Measuring the Well-Ordering of Bids

\begin{tabular}{lcccc}
\hline \hline \multicolumn{5}{c}{ Kendall-Tau Coefficient of Well-Ordering } \\
\hline & Obs & 2-Person Auction & 20-Person Auction & Difference \\
\hline Pooled $^{\dagger}$ & 900 & 0.546 & 0.585 & $-0.040^{* *}$ \\
& & $(0.014)$ & $(0.012)$ & $(p=0.11)$ \\
Pooled $^{\dagger \star}$ & \multirow{2}{*}{899} & 0.546 & 0.589 & $-0.043^{* * *}$ \\
& & $(0.014)$ & $(0.012)$ & $(p=0.004)$ \\
Per Period $^{\star}$ & \multirow{4}{*}{45} & 0.566 & 0.612 & $-0.042^{* * *}$ \\
& \multicolumn{5}{c}{$(0.014)$} & $(0.014)$ & $(p=0.005)$ \\
\hline${ }^{*} p<0.10,{ }^{* *} p<0.05,{ }^{* * *} p<0.01$ \\
$\dagger$ Standard errors clustered at the period level. $\star \$ 99$ bid omitted.
\end{tabular}

Our results show that neither auction is able to generate a perfect ordering of valuations based on bids. Observing a concordant pair of bids is 55\% more likely than observing a discordant pair of bids in the small auction and 59\% more likely in the large auction. This difference in relative likelihood is statistically significant and economically meaningful, as it leads to 365 more discordant pairs of bids.

Digging deeper into the K-T coefficients reveals some of the mechanisms that drive bids out of their well-ordered ranking. For bidders with similar valuations, Figure 1 shows that bids in the 2-Person Auction have a more gradual and consistent differences. On the other hand, expected bids from bidders with very distinct valuations show much starker differences in the 20-Person Auction.

Table 3: Kendall's Tau Coefficient for Ordering among Expected Winners and Losers

\begin{tabular}{lcccc}
\hline \hline & Obs & 2-Person Auction & 20-Person Auction & Difference \\
\hline Valuation $_{i}<10$ & 422 & 0.365 & 0.289 & $0.076^{* * *}$ \\
& & $(0.028)$ & $(0.028)$ & $(p=0.006)$ \\
$5<$ Valuation $_{i}<15$ & 477 & 0.401 & 0.479 & $-0.078^{* * *}$ \\
& & $(0.030)$ & $(0.021)$ & $(p=0.004)$ \\
$10<$ Valuation $_{i}$ & 477 & 0.333 & 0.342 & -0.008 \\
& & $(0.031)$ & $(0.027)$ & $(p=0.805)$ \\
\hline${ }^{*} p<0.10, * * p<0.05, * * * p 0.01$ & & &
\end{tabular}

$\$ 99$ bid omitted and standard errors clustered at the period level.

We divide bidders based on their valuations into ex-ante expected winners and losers. Those with valuations above the median should expect to win ex-ante, and those below should standard t-test on the difference between the pairs. 
expect to lose ex-ante. Rows 1 and 3 of Table 3 report the K-T coefficients within expected losers and winners, respectively. These within-group coefficients differ meaningfully from the pooled coefficients in Table 2, and are relatively more favorable towards the 2-Person Auction. Row 2 of Table 3 compares sorting between expected winners and losers while maintaining the same interval length. This between-group sorting strongly favors the 20Person Auction, indicating that the stark probabilistic distinction between expected winners and losers in the 20-Person Auction may have motivated a stronger separation in bids.

The two observed sorting mechanisms follow naturally from the model, which predicts that the large auction should see pooling among high- and low-valuation bidders but strong separation between the two groups, while the small auction should better separate bidders within those same groups. Interpreting Table 2 in light of the results from Table 3 indicates that the superior sorting between expected outcomes in the 20-Person Auction dominates the diminished sorting within expected outcomes, resulting in a better-ordered set of bids.

\section{Discussion}

Our results show that subjects are sensitive to changes in the number of competitors even when the proportion of winners remains constant. Moreover, the model provides useful benchmark predictions about the way subjects will adjust their behavior to the contest size.

Before discussing policy recommendations, it is important to note that our analysis explores the effect of contest size while holding all other inputs fixed. We abstract away from systematic correlations between the quality of inputs and the class size. Of course, in any discussion of policy these correlations will need to be weighed against our results about the strategic effects of class size on effort. This paper only identifies the potential for a strategic effect of class size and leaves it to further research to weave these strategic effects into the broader discussion of the effects of class size on performance. It is also important to note that we explore effort responses to large changes in the contest environment, thus our results 
should be adjusted to account for the actual change in class size being considered.

Looking only at these strategic effects, for classroom designers concerned with maximizing aggregate effort, we recommend larger class sizes, as our larger contests yielded greater aggregate bidding. Thus, we expect that students in classes graded on the curve will increase effort as the class size grows. In smaller contests, we find that the greater uncertainty about the effort required for a given grade causes participants to strategically lower their effort in an attempt to exploit the randomness of the environment. Larger classes hold less uncertainty about the effort required for a given grade, and we expect students to respond with increases in effort just large enough to meet the effort required for their desired grade.

A designer may also have preferences over the distribution of effort across students with different abilities. We found that this distribution of effort is strongly affected by the size of the contest. From our results, we expect that high ability students will exert greater effort in larger classes, while students with lower-middle abilities may exert slightly more effort in smaller classes. Our results also suggest that the lowest ability students will not be sensitive to changes in the size of the strategic environment.

Larger classes may also have an advantage with respect to the ability to sort students by their classroom performance. Since student abilities are unobservable, classroom performance must serve as a sorting mechanism that distinguishes relative ability. We discovered that the ability of a relative grading scheme to accurately sort students may be systematically undermined in courses with low enrollment, creating an environment where a student's ability is less correlated to her relative performance.

While this paper analyzes the motivating effects of class size when graded in a binary manner (e.g. "pass" or "fail"), the majority of courses have finer grade differentiation (e.g. A,B,C,D,F). These multi-tiered environments would simply break the larger contest into several smaller contests between grade levels. As such, we do not believe this would affect the qualitative predictions of the model. A student at the 90th percentile will compete with other high-ability students for A's in the same way that median students in our experiment 
compete for "pass" grades. With a finer grading scheme, low enrollment courses have an even larger effect on the uncertainty each student faces with regards to their draw of classmates and their relative ability. Our results indicate that this uncertainty may cause effort to diminish and further weaken the correlation between ability and performance. On the other hand, with large enough enrollment, we still expect students to just match the effort required for a given grade. For example, the top student in a class of 500 may pool with the other high-ability students just above the cutoff for A's. ${ }^{28}$ The ordering of students under this finer grading scheme will depend more heavily on sorting across expected outcomes, giving a further advantage to large courses. This is largely speculative, however, and needs to be verified by further studies.

\section{Conclusions}

We designed and executed an experiment to examine how the size of a contest affects the effort choices by contestants with different abilities. We used an all-pay auction format to measure effort in auctions with different sizes. We used a paired auction design to abstract away from the exacting question of equilibrium bidding levels and focus on how bidding changes with auction size. We broke these changes down by ability level and showed the model's ability to qualitatively predict how bidding differences would evolve with ability. Our results hold economically and statistically significant implications for a broad category of mechanism design.

The theoretical bidding functions we developed correctly predicted that larger auctions elicit greater aggregate bidding as well as higher bids from high-ability bidders. The model draws attention to the uncertainty that arises as the size of an auction decreases. This uncertainty not only drives down bids from high-ability bidders, but also limits the ability of the designer to accurately order bidders' valuations based on their bids.

As policy makers, administrators, and other mechanism designers continue to employ

\footnotetext{
${ }^{28}$ For a discussion of the optimal fineness of a grading scheme, see Dubey and Geanakoplos (2010).
} 
relative awarding schemes, our research sheds light on the effect that the number of participants has on the effort exerted in the mechanism. While this study considered only two sizes in a stylized contest, we believe it serves as a strong foundation for further research on the independent effect of a contest's size on the performance of its participants. 


\section{References}

Amann, E., \& Leininger, W. (1996). Asymmetric All-Pay Auctions with Incomplete Information: The Two-Player Case, Games and Economic Behavior, 14, 1-18.

Andreoni, J., Che, Y. K., \& Kim, J. (2007). Asymmetric information about rivals' types in standard auctions: An experiment. Games and Economic Behavior, 59(2), 240-259.

Andreoni, J. \& Harbaugh, W. (2016). Unexpected Utility: Experimental Tests of Five Key Questions about Preferences over Risk. Mimeo.

Athey, S. (2001). Single Crossing Properties and the Existence of Pure Strategy Equilibria in Games of Incomplete Information. Econometrica, 69(4), 861-889.

Baik, K. H. (1994). Effort levels in contests with two asymmetric players. Southern Economic Journal, 367-378.

Barut, Y., Kovenock, D., \& Noussair, C., (2002). A comparison of multiple-unit all-pay and winner-pay auctions under incomplete information. International Economic Review 43, 675-707.

Baye, M., Kovenock, D. \& de Vries, C.G. (1996). The All-Pay Auction with Complete Information. Economic Theory, 8, 291-305.

Baye, M., Kovenock, D. \& de Vries, C.G. (1993). Rigging the lobbying process: an application of the all-pay auction. American Economic Review, 83, 289-294.

Becker, W.E., \& Rosen, S. (1992). The Learning Effect of Assessment and Evaluation in High School. Economics of Education Review 11, 2, 107-18.

Bertrand, M., Duflo, E., \& Mullainathan, S. (2004). How much should we trust differencesin-differences estimates?. The Quarterly Journal of Economics, 119(1), 249-275.

Davis, D. \& Reilly, R. (1998). Do Many Cooks Always Spoil the Stew? An Experimental Analysis of Rent Seeking and The Role of A Strategic Buyer. Public Choice, 95, 89-115.

Dechenaux, Kovenock, and Sheremeta (2012). A Survey of Experimental Research on Contests, All-Pay Auctions and Tournaments. mimeo. 
Dubey, P. \& Geanakoplos, J. (2010). Grading Exams: 100,99,98,... or A,B,C? Games and Economic Behavior, 69, 72-94.

Fischbacher, U. (2007). z-Tree: Zurich toolbox for ready-made economic experiments. Experimental Economics 10, 171-178.

Gneezy, U. \& Smorodinsky, R. (2006). All-Pay Auctions-An Experimental Study. Journal of Economic Behavior and Organization, 61, 255-275.

Harbring, C. \& Irlenbusch, B. (2005). Incentives in Tournaments with Endogenous Prize Selection. Journal of Institutional and Theoretical Economics, 127, 636-663.

Hillman, A. \& Riley, J.G. (1989). Politically contestable rents and transfers. Economics and Politics, 1, 17-40.

Kagel, J. H., \& Levin, D. (1993). Independent private value auctions: Bidder behaviour in first-, second-and third-price auctions with varying numbers of bidders. The Economic Journal, 868-879.

Kendall, M.G., (1938). A new measure of rank correlation. Biometrika, Vol 30, 1938, 81-93.

Kendall M. G. (1970). Rank correlation methods, fourth ed., Charles Griffin \& Co., London.

Krishna, V. \& Morgan, J. (1997). An Analysis of the War of Attrition and the All-Pay Auction Journal of Economic Theory. 72, 343-362.

Krueger, A.O. (1974). The Political Economy of the Rent-Seeking Society. American Economic Review. 64, 291-303.

Lazear, E.P. \& Rosen, S. (1981). Rank-Order Tournaments as Optimum Labor Contracts. Journal of Political Economy, 89, 841-864.

Lim, W., Matros, A. \& Turocy, T. (2014). Bounded rationality and group size in Tullock contests: Experimental evidence. Journal of Economic Behavior and Organization, 99, 155-167.

Minor, D. (2012). Coarse Strategy and Competition. mimeo.

Moldovanu, B. \& Sela, A. (2001) The optimal allocation of prizes in contests. American Economic Review, 91, 542-558. 
Moldovanu, B. \& Sela, A. (2006) Contest Architecture. Journal of Economic Theory, 126(1), 70-96.

Müller, W. \& Schotter, A. (2010). Workaholics and Dropouts in Organizations. Journal of the European Economic Association, 8, 717-743.

Noussair, C. \& Silver, J. (2006). Behavior in All Pay Auctions with Incomplete Information. Games and Economic Behavior, 55, 189-206.

Olszewski, W. \& Siegel, R. (2013). Large Contests. Mimeo.

Orrison, A., Schotter, A. \& Weigelt, K. (2004). Multiperson Tournaments: An Experimental Examination. Management Science, 1-10.

Parreiras, S. O. \& Rubinchik, A. (2010). Contests with three or more heterogeneous agents. Games and Economic Behavior, 68(2), 703-715.

Potters, J.C., de Vries, C.G. \& van Winden, F. (1998). An Experimental Examination of Rational Rent Seeking. European Journal of Political Economy, 14, 783-800.

Spearman, C. (1904). The proof and measurement of correlation between two things. American Journal of Psychology, 15, 72-101.

Tullock, G. (1967). The Welfare Costs of Tariffs, Monopolies, and Theft. Western Economic Journal, 5, 224-232. 


\section{Appendix}

To Accompany J. Andreoni and A. Brownback

"All Pay Auctions and Group Size: Grading on a Curve and other Applications"

For online publication only.

\section{A1: Proofs}

Proposition 1: Optimal Bidding Function is Weakly Monotonic in Valuation.

Proof: Suppose not. Then $v_{i}$ and $v_{j}$ exist such that: $v_{i}<v_{j}$ but $b_{i}>b_{j}$.

Incentive compatibility for $i$ dictates that

$$
U\left(b_{i}, v_{i}, N\right) \geq U\left(b_{j}, v_{i}, N\right)
$$

Substituting in the bidder's utility yields

$$
v_{i} * P_{N}\left(b_{i}\right)-b_{i} \geq v_{i} * P_{N}\left(b_{j}\right)-b_{j},
$$

and rearranging we find

$$
b_{i}-b_{j} \leq v_{i}\left(P_{N}\left(b_{i}\right)-P_{N}\left(b_{j}\right)\right)
$$

A similar derivation for $j$ reveals

$$
b_{i}-b_{j} \geq v_{j}\left(P_{N}\left(b_{i}\right)-P_{N}\left(b_{j}\right)\right) .
$$

Therefore, since $b_{i}>b_{j}$, by construction this implies $P_{N}\left(b_{i}\right) \geq P_{N}\left(b_{j}\right)$. Subsequently, we have

$$
v_{i}\left(P_{N}\left(b_{i}\right)-P_{N}\left(b_{j}\right)\right) \geq v_{j}\left(P_{N}\left(b_{i}\right)-P_{N}\left(b_{j}\right)\right) .
$$

Thus, $v_{i} \geq v_{j}$ or $P_{N}\left(b_{i}\right)=P_{N}\left(b_{j}\right)$. In the case of the former we have a contradiction. In 
the case of the latter, our contradiction is satisfied by a violation of incentive compatibility. Hence, $v_{i}<v_{j} \Longrightarrow b_{i} \leq b_{j}$. QED.

Corollary 1: Monotonicity holds under Risk Aversion

Proof: Again we start with:

$$
U\left(b_{i}, v_{i}, N\right) \geq U\left(b_{j}, v_{i}, N\right)
$$

and

$$
U\left(b_{j}, v_{j}, N\right) \geq U\left(b_{i}, v_{j}, N\right) .
$$

Expand to

$$
U\left(v_{i}-b_{i}\right) * P_{N}\left(b_{i}\right)+U\left(-b_{i}\right)\left(1-P_{N}\left(b_{i}\right)\right) \geq U\left(v_{i}-b_{j}\right) * P_{N}\left(b_{j}\right)+U\left(-b_{j}\right)\left(1-P_{N}\left(b_{j}\right)\right)
$$

and

$$
U\left(v_{j}-b_{j}\right) * P_{N}\left(b_{j}\right)+U\left(-b_{j}\right)\left(1-P_{N}\left(b_{j}\right)\right) \geq U\left(v_{j}-b_{i}\right) * P_{N}\left(b_{i}\right)+U\left(-b_{i}\right)\left(1-P_{N}\left(b_{i}\right)\right) .
$$

Solving for common terms and combining yields

$$
\begin{aligned}
U\left(v_{i}-b_{i}\right) * P_{N}\left(b_{i}\right)+ & U\left(-b_{i}\right)\left(1-P_{N}\left(b_{i}\right)\right)-U\left(v_{i}-b_{j}\right) * P_{N}\left(b_{j}\right) \geq \\
& U\left(v_{j}-b_{i}\right) * P_{N}\left(b_{i}\right)+U\left(-b_{i}\right)\left(1-P_{N}\left(b_{i}\right)\right)-U\left(v_{j}-b_{j}\right) * P_{N}\left(b_{j}\right) .
\end{aligned}
$$

Canceling terms and grouping simplifies this to

$$
P_{N}\left(b_{i}\right)\left[U\left(v_{i}-b_{i}\right)-U\left(v_{j}-b_{i}\right)\right] \geq P_{N}\left(b_{j}\right)\left[U\left(v_{i}-b_{j}\right)-U\left(v_{j}-b_{j}\right)\right] .
$$

We have assumed $v_{j}>v_{i}$ and $b_{i}>b_{j}$, so we can define $v_{i}-b_{i} \equiv A, v_{j}-b_{i} \equiv A^{\prime}$, 
$v_{i}-b_{j} \equiv B$, and $v_{j}-b_{j} \equiv B^{\prime}$ with $A^{\prime}>A, B^{\prime}>B$, and $B>A$ :

$$
P_{N}\left(b_{i}\right)\left[U(A)-U\left(A^{\prime}\right)\right] \geq P_{N}\left(b_{j}\right)\left[U(B)-U\left(B^{\prime}\right)\right]
$$

But, since $A^{\prime}-A=B^{\prime}-B$ and $U^{\prime \prime}<0$ we know

$$
\left[U(A)-U\left(A^{\prime}\right)\right]<\left[U(B)-U\left(B^{\prime}\right)\right]<0 .
$$

Our assumptions also tell us that $P_{N}\left(b_{j}\right)<P_{N}\left(b_{i}\right)$,meaning

$$
P_{N}\left(b_{i}\right)\left[U(A)-U\left(A^{\prime}\right)\right]<P_{N}\left(b_{j}\right)\left[U(B)-U\left(B^{\prime}\right)\right],
$$

and we arrive at a contradiction. QED.

Prediction 1: Aggregate bidding increases with the auction size

We find the expected revenue from each auction by calculating the expected bid and multiplying by the number of bidders. The expected bids are given by:

$$
\begin{gathered}
\mathbb{E}\left[b_{2,1}\right]=\int_{0}^{1} B_{2,1}\left(v_{i}\right) f\left(v_{i}\right)=\left.\frac{v_{i}^{3}}{6}\right|_{0} ^{1}=\frac{1}{6} \approx 0.167 \\
\mathbb{E}\left[b_{20,10}\right]=\int_{0}^{1} B_{20,10}\left(v_{i}\right) f\left(v_{i}\right)=-\frac{46189 v_{i}^{21}}{21}+21879 v_{i}^{20}-97240 v_{i}^{19} \\
\quad+\frac{760760 v_{i}^{18}}{3}-\frac{855855 v_{i}^{17}}{2}+\frac{969969 v_{i}^{16}}{2}-369512 v_{i}^{15} \\
+ \\
+\frac{1279080 v_{i}^{14}}{7}-53295 v_{i}^{13}+\left.\frac{20995 v_{i}^{12}}{3}\right|_{0} ^{1}=\frac{5}{21} \approx 0.238
\end{gathered}
$$

Thus, the expected revenue from the scaled-down version of the 2- and 20-person auctions are $20 \times \mathbb{E}\left[b_{2,1}\right]=\frac{10}{3}$ and $20 \times \mathbb{E}\left[b_{20,10}\right]=\frac{100}{21}$, respectively. Scaling each auction up by 20 to reflect the experimental valuations yields predictions for the total revenues in the experimental auctions: $\frac{200}{3} \approx 66.67$ and $\frac{2000}{21} \approx 95.238$. 
More generally, Moldovanu and Sela (2006) explore auctions with an isomorphic structure (independent private bidding cost instead of our independent private value). They show that show that the expected revenue from an auction with $N$ bidders and $P$ prizes is equal to $\mathbb{E}\left[\frac{1}{C_{(P+1, N)}}\right]$, where $C_{(p+1, n)}$ is the order statistic for the cost of the $P+1$-th highest-cost bidder. That is, expected revenue is equal to the inverse of the expected cost of the lowestcost bidder who does not win a prize. Translating this into our context, it means that the expected revenue will be $\mathbb{E}\left[V_{N-P, N}\right]$. That is, revenue is equal to the expected valuation of the most competitive loser of the auction.

Since our valuations are drawn uniformly $\left(v_{i} \sim U[0,1]\right)$, this order statistic has a known distribution. With $N$ draws from the distribution, the expected value of the $N / 2$-th order statistic is $\frac{N / 2}{N+1}$. As the auction size grows $(N \rightarrow \infty)$, the expected value of this order statistic converges monotonically to $\frac{1}{2}$ from below.

Prediction 2: Bidding functions cross from below exactly once

We consider two independent private value auctions with valuations drawn uniformly $v_{i} \sim[0,1]$. One auction has $N$ bidders and $N / 2$ prizes and the other has $M>N$ bidders and $M / 2$ prizes. We claim that, the predicted bidding functions for the two auction sizes cross exactly once on the interior of the set of abilities with the predicted bids from the larger auction crossing the predicted bids of the smaller auction from below.

Our proof of the single-crossing property of bidding functions will follow closely the proof from the appendix of Moldovanu and Sela (2006). The proof begins by showing that the predicted bids from the larger auction are smaller for bidders with abilities in a neighborhood of the lower bound and that bids are larger for bidders with abilities in a neighborhood of the upper bound. This is sufficient to show at least one crossing of the bidding functions. We will then demonstrate the equality of slopes at a unique point over the space of abilities. We complete the proof by invoking Rolle's Theorem to show that multiple crossing points imply multiple points where the slopes must be equal, contradicting the previous step.

To begin, we consider bids from bidders with abilities at the lower bound, $v_{i}=0$. In 
both cases, bids are predicted to be equal $B_{M, M / 2}(0)=B_{N, N / 2}(0)=0$. This results from the dominance argument made in Section 3. Instead of considering bidding at exactly $v_{i}=0$, we focus on the limit of the ratio of the two bidding functions as valuations approach the lower bound: $\lim _{v \rightarrow 0} \frac{B_{M, M / 2}(v)}{B_{N, N / 2}(v)}$. Since this limit does not exist, we invoke L'Hopital's rule and consider the limit of the derivatives: $\lim _{v \rightarrow 0} \frac{B_{M, M / 2}^{\prime}(v)}{B_{N, N / 2}^{\prime}(v)}$. These derivatives are presented in Equations 9 and 10, below:

$$
\begin{aligned}
& B_{M, M / 2}^{\prime}\left(v_{i}\right)=\sum_{k=M / 2}^{M-1}\left\{\left(\frac{(M-1) !}{(M-1-k) ! k !}\right) v_{i}^{k}\left(1-v_{i}\right)^{M-2-k}\left[k\left(1-v_{i}\right)-(M-1-k) v_{i}\right]\right\} \\
& B_{N, N / 2}^{\prime}\left(v_{i}\right)=\sum_{k=N / 2}^{N-1}\left\{\left(\frac{(N-1) !}{(N-1-k) ! k !}\right) v_{i}^{k}\left(1-v_{i}\right)^{N-2-k}\left[k\left(1-v_{i}\right)-(N-1-k) v_{i}\right]\right\}
\end{aligned}
$$

Notice that both derivatives are again equal to 0 . In fact, it holds that all derivatives of $B_{N, N / 2}^{(i)}$ of order $i$ where $i<N-1$ and all derivatives of $B_{M, M / 2}^{(i)}$ of order $i$ where $i<M-1$ are equal to zero. Therefore, $\lim _{v \rightarrow 0} \frac{B_{M, M / 2}^{(N-1)}(v)}{B_{N, N / 2}^{(N-1)}(v)}=\frac{0}{C}$ where $C$ is a constant. Meaning that $B_{M, M / 2}(\epsilon)<B_{N, N / 2}(\epsilon)$ for an $\epsilon$ sufficiently close to 0 .

Moldovanu and Sela (2006) show that bids cast by bidders at the lower bound of costs, $m$, are equal to $B_{N, P}(m)=\mathbb{E}\left[\frac{1}{C_{(P, N-1)}}\right]$. Adapting that to our framework yields the result that bids at the upper bound of valuations, 1 , are equal to $B_{N, P}(1)=\mathbb{E}\left[V_{(P, N-1)}\right]$. Since valuations are drawn uniformly from the unit inverval, this order statistic is known to be $\mathbb{E}\left[V_{(P, N-1)}\right]=\frac{P}{N}$. With $P=N / 2$, we get that $B_{N, N / 2}(1)=\frac{1}{2} \forall N$. This means that $B_{M, M / 2}(1)=B_{N, N / 2}(1)$.

Since all bidding functions are equal at the upper bound, we must show that $B_{M, M / 2}(1-$ $\epsilon)>B_{N, N / 2}(1-\epsilon)$ for a sufficiently small $\epsilon$. Again, we invoke L'Hopital's Rule to explore $\lim _{v \rightarrow 1} \frac{1 / 2-B_{M, M / 2}(v)}{1 / 2-B_{N, N / 2}(v)}$. By the same process as above, we arrive at $\lim _{v \rightarrow 1} \frac{B_{M, M / 2}^{(N / 2-1)}(v)}{B_{N, N / 2}^{(N / 2-1)}(v)}=\frac{0}{C}$, meaning that the bidding function converges to $1 / 2$ faster in larger auctions. 
We have now demonstrated that $B_{M, M / 2}(\epsilon)<B_{N, N / 2}(\epsilon)$ and $B_{M, M / 2}(1-\epsilon)>B_{N, N / 2}(1-\epsilon)$ for a sufficiently small $\epsilon$. Given the continuous nature of these bidding functions, this is sufficient to show that the two bidding functions intersect at least once for $v^{*} \in(0,1)$. We will now demonstrate that this intersection is unique.

Given that $B_{M, M / 2}(\epsilon)<B_{N, N / 2}(\epsilon)$ and $B_{M, M / 2}(1-\epsilon)>B_{N, N / 2}(1-\epsilon)$, for our bidding functions to intersect more than once over the interval $(0,1)$, they must intersect at least 3 times otherwise, one of the previous inequalities would be violated. We will prove that this cannot be the case by way of contradiction.

Suppose there exists a set $v=\left\{v_{1}, v_{2}, v_{3}\right\}$ with $v_{1}<v_{2}<v_{3}, v_{i} \in(0,1) \forall i=1,2,3$, and $B_{M, M / 2}\left(v_{i}\right)=B_{N, N / 2}\left(v_{i}\right) \forall i=1,2,3$. Since the bidding functions are continuous, Rolle's theorem states that the slopes of the two functions must be equal at least once between every two adjacent intersection points. That is, there must exist a set of points $d=\left\{d_{1}, d_{2}, d_{3}, d_{4}\right\}$ with $d_{1} \in\left(0, v_{1}\right), d_{2} \in\left(v_{1}, v_{2}\right), d_{3} \in\left(v_{2}, v_{3}\right), d_{4} \in\left(v_{3}, 1\right)$ and $B_{M, M / 2}^{\prime}\left(d_{i}\right)=B_{N, N / 2}^{\prime}\left(d_{i}\right) \forall i=$ $1,2,3,4$.

To prove the equality of slopes without going into unnecessary detail, we will conduct the proof using the functional forms from Moldovanu and Sela (2006), which are isomorphic to our environment. This proof is nearly identical to the proof of Lemma 1 in their appendix. In their model, the value of a prize is divided by the number of available prizes, we will remove this feature.

They show that $B_{N, P}^{\prime}(d)=\frac{1}{d} d F_{(P, N-1)}(d) F^{\prime}(d)$, where $d F_{(P, N-1)}(d)$ is the derivative of the distribution of the $P$-th order statistic of a contest with $N$ bidders. Specifically, $d F_{(P, N-1)}(d)=\frac{(N-1) !}{(P-1) !(N-P-1) !} F^{P-1}(d)(1-F(d))^{N-P-1} F^{\prime}(d)$. Thus: 


$$
\begin{array}{r}
B_{M, M / 2}^{\prime}(d)-B_{N, N / 2}^{\prime}(d) \\
=\frac{1}{d} d F_{(M / 2, M-1)}(d) F^{\prime}(d)-\frac{1}{d} d F_{(N / 2, N-1)}(d) F^{\prime}(d) \\
=\frac{1}{d} \frac{(M-1) !}{(M / 2-1) !(M / 2-1) !} F^{M / 2-1}(d)(1-F(d))^{M / 2-1} F^{\prime}(d) \\
-\frac{1}{d} \frac{(N-1) !}{(N / 2-1) !(N / 2-1) !} F^{N / 2-1}(d)(1-F(d))^{N / 2-1} F^{\prime}(d) \\
=\frac{1}{d} F^{N / 2-1}(d)(1-F(d))^{N / 2-1} F^{\prime}(d) \\
{\left[\frac{(M-1) !}{[(M / 2-1) !]^{2}} F^{\frac{M-N}{2}}(d)(1-F(d))^{\frac{M-N}{2}}-\frac{(N-1) !}{[(N / 2-1) !]^{2}}\right]}
\end{array}
$$

Thus, the slopes are equal whenever the following hold:

$$
\begin{gathered}
\frac{(M-1) !}{[(M / 2-1) !]^{2}} F^{\frac{M-N}{2}}(d)(1-F(d))^{\frac{M-N}{2}}=\frac{(N-1) !}{[(N / 2-1) !]^{2}} \\
F^{\frac{M-N}{2}}(d)(1-F(d))^{\frac{M-N}{2}}=\frac{(N-1) ![(M / 2-1) !]^{2}}{[(N / 2-1) !]^{2}(M-1) !} \\
F(d)-F^{2}(d)=\left[\frac{(N-1) ![(M / 2-1) !]^{2}}{[(N / 2-1) !]^{2}(M-1) !}\right]^{\frac{2}{M-N}}
\end{gathered}
$$

Let $\bar{C}=\left[\frac{(N-1) ![(M / 2-1) !]^{2}}{[(N / 2-1) !]^{2}(M-1) !}\right]^{\frac{2}{M-N}}$. Notice that $\bar{C}$ is a positive constant. Additionally, since $F(d)$ monotonically maps values from the unit interval to the unit interval $(F:[0,1] \rightarrow[0,1])$, $F(d)-F^{2}(d)$ can take on the value of any positive constant at most twice, contradicting our assumption of four or more solutions to Equation 11.

\section{A2: Alternative Assumptions on Utility}

Here we reconsider our model under assumptions of risk averse bidders, and bidders with a joy-of-winning. 


\section{Risk Averse Bidding Functions}

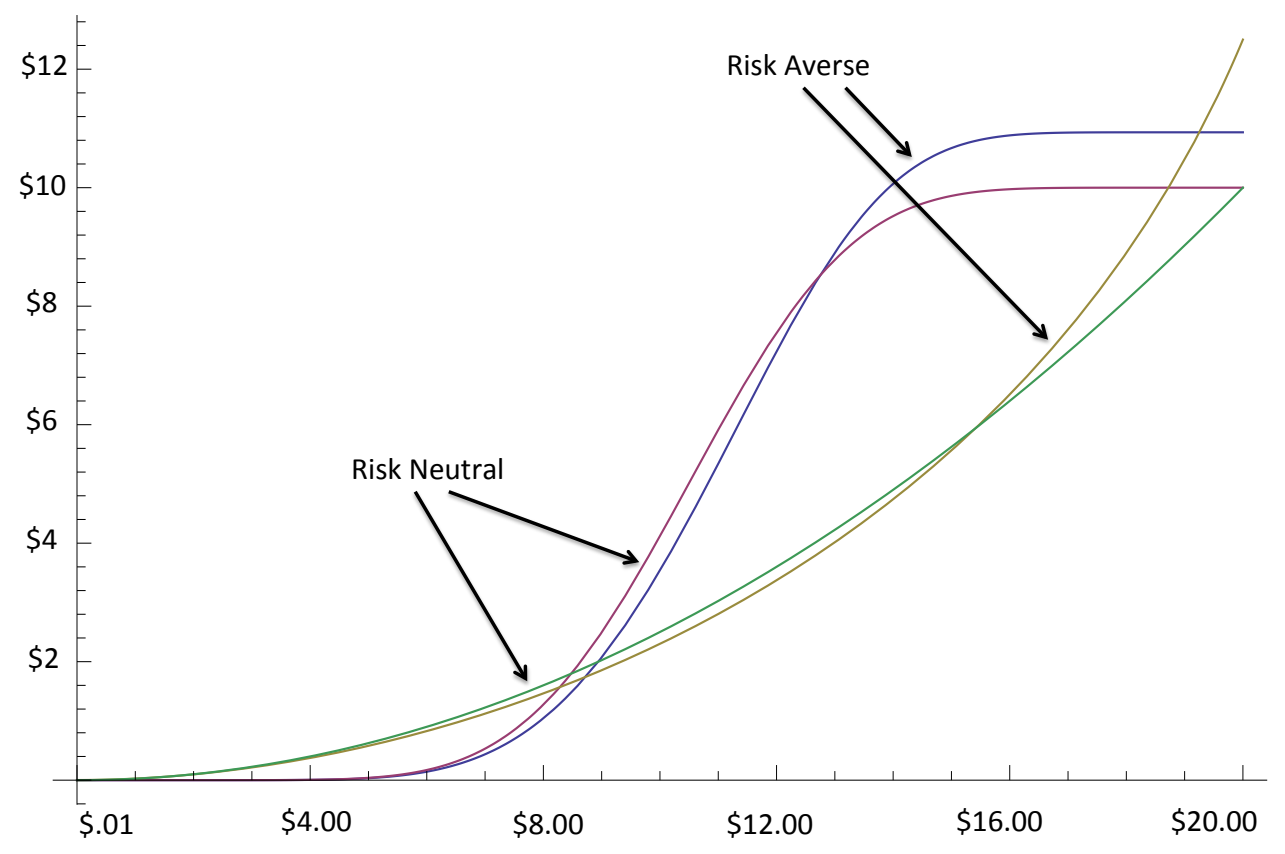

Figure 6: Risk Averse Bidding Equilibrium

This graph details the bidding function under CRRA utility of $U(x)=\frac{x^{1-\sigma}}{1-\sigma}$ with $\sigma=3$. Here we can see that the risk aversion does not strongly affect the shape or magnitude of the bidding function in a symmetric equilibrium. Moreover, the risk averse Nash Equilibrium deviates from the data even more than does the risk neutral Nash Equilibrium over middle valuations.

\section{Joy of Winning}

We can modify our optimal bidding framework to include a constant utility gain simply from winning an auction. This will result in the following utility function:

$$
U(\bullet)=\left(v_{i}+c\right) * P_{N}\left(b_{i}\right)-b_{i}
$$


Resulting in the following bidding functions:

$$
\begin{aligned}
B\left(v_{i}, 2\right)= & \frac{v_{i}^{2}}{2}+c v_{i} \\
B\left(v_{i}, 20\right)= & -\left(\frac{1}{2}\right) x^{10}\left\{2 c \left(48620 x^{9}-461890 x^{8}+1956240 x^{7}-4849845 x^{6}+7759752 x^{5}\right.\right. \\
& \left.-8314020 x^{4}+5969040 x^{3}-2771340 x^{2}+755820 x-92378\right) \\
& +x\left(92378 x^{9}-875160 x^{8}+3695120 x^{7}-9129120 x^{6}+14549535 x^{5}\right. \\
& \left.\left.-15519504 x^{4}+11085360 x^{3}-5116320 x^{2}+1385670 x-167960\right)\right\}
\end{aligned}
$$

Figure 2 shows the equilibrium that arises under a modest value for the Joy of Winning parameter, $c=\$ 1.00$.

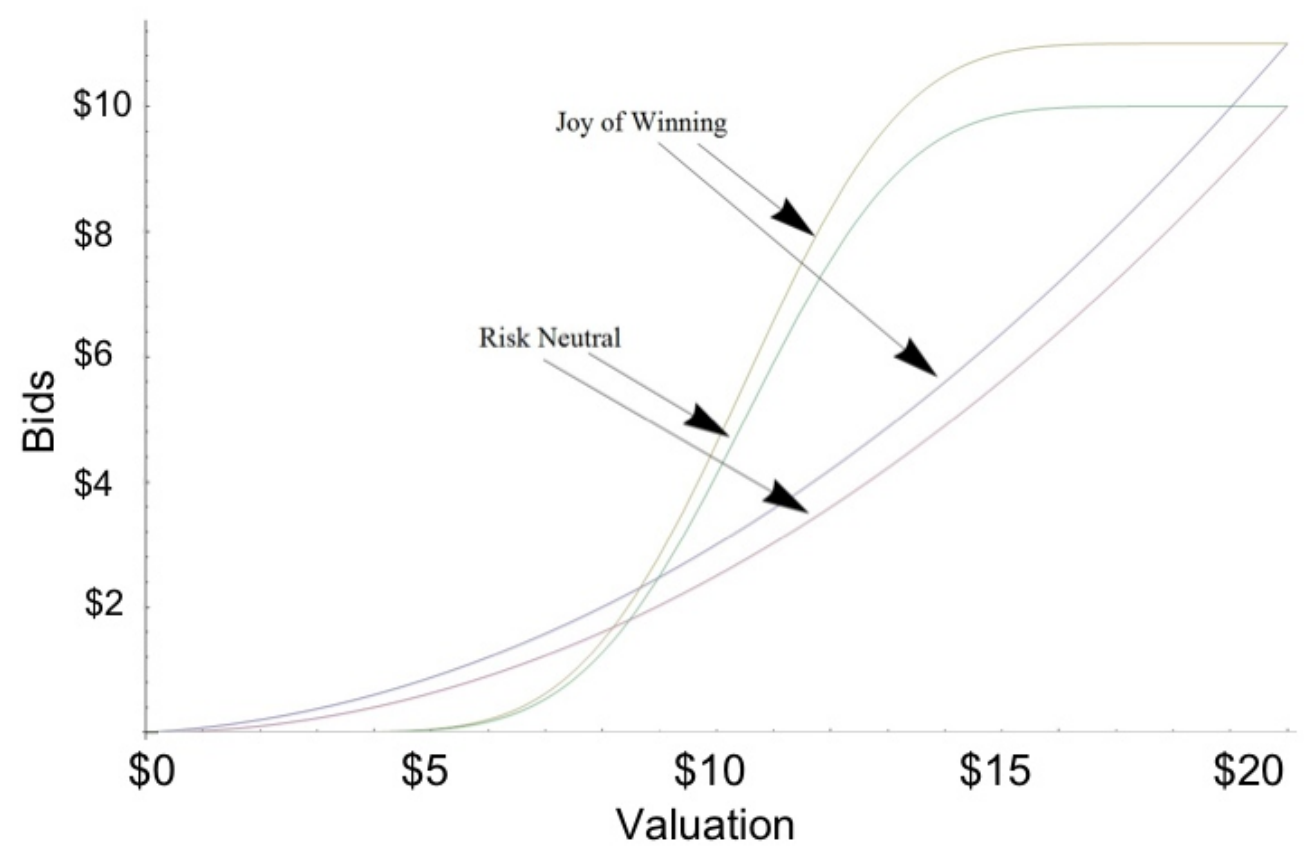

Figure 7: Joy of Winning Equilibrium 


\section{A3: Additional Analysis}

Table 4: Difference in bids (2-Person Auction bid - 20-Person Auction bid)

\begin{tabular}{lccc}
\hline \hline \multirow{2}{*}{ Periods: } & \multicolumn{3}{c}{ Predicted Cutoff: $\$ 8.48$} \\
\cline { 2 - 3 } & $1-15$ & $1-15$ & $1-20$ \\
\hline LowerBin=1 & 0.0816 & -0.188 & 0.074 \\
if $V_{i} \leq \$ 8.48$ & $(0.10)$ & $(0.30)$ & $(0.09)$ \\
& & & \\
UpperBin=1 & $-0.997^{* * *}$ & $-0.957^{* * *}$ & -1.060 \\
if $V_{i}>\$ 8.48$ & $(0.31)$ & $(0.29)$ & $(0.29)$ \\
\hline $\mathrm{N}$ & 899 & 900 & 1059 \\
\hline${ }^{*} p<0.10,{ }^{* *} p<0.05,{ }^{* * *} p<0.01$ \\
Standard errors clustered by subject.
\end{tabular}

In column 1 of Table 4, we see the original analysis from Table 1. Column 2 includes the $\$ 99$ bid that guaranteed the subject a loss of $\$ 98.62$. The two regions are still significantly different from each other at the 5\% level. Column 3 includes rounds 16-20 of session 1 to show that the difference between the two regions grows larger. 


\section{A4: Subjects' Instructions}

Before the experiment, subjects were given two sheets of paper to facilitate understanding of the experiment. The first page defined a list of terms that we would refer to throughout the experiment. The second page outlined logistics of the experiment with respect to how payments were determined. The two pages are found in the two following subsections.

\section{Definitions}

These terms were used throughout the experiment. We gave all subjects a hard copy reference sheet that they could use for clarification of the instructions.

Prize Value: In each auction you will be assigned a "prize value" this is the amount of money that you will win if you receive a prize in that auction. So, if your prize value is $\$ 6.76$ then you will receive $\$ 6.76$ if you win that auction. If your prize value is $\$ 19.95$ then you will receive $\$ 19.95$ if you win that auction, and so on.

Bid: In each auction you must bid in order to win a prize. Prizes will be awarded to the participants with the highest bids. If there is one prize in the auction then the prize will go to the highest bidder. If there are ten prizes in the auction then they will go to the ten highest bidders, and so on.

NOTE: You must pay your bid regardless of the outcome of the auction. Whether you win or you lose you will be charged your bid. If you bid $\$ 5.34$ in an auction and you lose then you will be charged \$5.34. Likewise, if you bid $\$ 5.34$ in an auction and you win then you will be charged $\$ 5.34$.

Payout: The amount of money you gain from an auction will depend on your bid and your prize value. If you win then you will receive your prize value and you 
will be charged your bid. If you lose then you will receive nothing and you will still be charged your bid.

EXAMPLE: If you have a prize value of $\$ 15.00$ and you bid $\$ 10.00$ and you win the auction then you will receive your prize value, $\$ 15.00$, and you will be charged your bid, $\$ 10.00$, meaning that your payout will be (positive) $\$ 5.00$.

EXAMPLE: If you have a prize value of $\$ 15.00$ and you bid $\$ 10.00$ and you lose the auction then you will receive nothing and you will be charged your bid, $\$ 10.00$, meaning that your payout will be (negative) $-\$ 10.00$.

Auction That Counts: After you have completed the experiment, one round will be selected at random to be the Auction That Counts. The Auction That Counts will determine part of your Take-Home Pay and your Payout from the Auction That Counts could be positive or negative. We select one round at random as the Auction That Counts so that no participant accumulates too many losses and has a negative Take-Home Pay. Also, we select the Auction That Counts randomly so that you take every round seriously because it could be the Auction That Counts.

Take-Home Pay: You will receive a $\$ 20.00$ show-up fee for participating today. In addition to this show-up fee, we will combine your Payout from the Money Auction to your $\$ 20$ show-up fee to determine your Take-Home Pay.

\section{Instructions:}

The page shown below explained the means by which we would calculate payments for each subject. All subjects were given a hard copy of this sheet for their reference. 


\section{$\underline{\text { Experimental Instructions }}$}

Thank you for volunteering for our experiment! Today you will participate in several different auctions in order to win money. The auctions will not be standard auctions, however, so there are some things that you need to keep in mind:

- Participation Payment: The payment for participating today is $\$ 20$.

- Auctions: Today's auctions will be different from normal auctions. Like all auctions, you will bid money in order to win a prize and the prizes will go to the highest bidders. However, the number of bidders and the number of prizes will change. The first type of auction will have 2 people bidding for 1 prize. In these auctions the pairs will be randomly reassigned each round. The second type of auction will have 20 people bidding for 10 prizes.

- Bid: In each auction you will specify a bid in order to win a prize. You must pay your bid regardless of the outcome of the auction so choose carefully. Whether you win or you lose you will be charged your bid.

○ EXAMPLE: If you bid \$5.34 in an auction and you lose, you will be charged $\$ 5.34$. Likewise, if you bid $\$ 5.34$ in an auction and you win, you will be charged $\$ 5.34$.

- Winning Bid: If there are more bids below your bid than above it, your bid is declared a Winning Bid and you will receive a prize. That is, if your bid is greater than half of the bids in the auction then you have a Winning Bid.

○ EXAMPLE: In a 2-Person auction your bid must be higher than the other bid to be a Winning Bid. In a 20-Person auction your bid must be among the 10 highest bids to be a Winning Bid.

- Ties: The computer will randomly break ties between equal bids.

- Prize Value: The "prizes" in these auctions will be worth a certain amount of money, and this amount will be different for each bidder. Every round you will be assigned a new "Prize Value." This Prize Value is the amount of money that you will win if you have a Winning Bid in the auction.

○ Possible Values: Prize Values are between \$0.01 and \$20.00 and every amount of money between them is equally likely. On average, half of the Prize Values will be above $\$ 10.00$ and half of the Prize Values will be below $\$ 10.00$ but the actual numbers will vary.

- Hidden Values: You will see your Prize Value but will not see anyone else's Prize Value. Likewise, no one will see your Prize Value but you. All prize values will be drawn in the same way as yours. 


\section{Pre-Experiment Quiz}

1. Suppose I have a prize value of $\$ 6.25$ and I bid $\$ 5.00$

a. If I win my payout will be:

b. If I lose my payout will be:

2. Suppose I have a prize value of $\$ 12.12$ and I bid $\$ 15.00$

a. If I win my payout will be:

b. If I lose my payout will be:

3. Suppose I am in an auction with 2 players and 1 prize. If I have a prize value of $\$ 10.50$ and I bid $\$ 9.00$ and my opponent bids $\$ 10.00$.

a. My payout will be:

4. Suppose I am in an auction with 2 players and 1 prize. If I have a prize value of $\$ 7.25$ and I bid $\$ 6.00$ and my opponent bids $\$ 5.00$.

a. My payout will be:

5. Suppose I am in an auction with 20 players and 10 prizes. If I have a prize value of $\$ 14.75$ and I bid $\$ 8.00$ and my opponents' bids are (in increasing order): $\$ 0 \$ 1.53 \$ 2.01 \$ 2.75 \$ 3.00 \$ 4.40 \$ 4.83 \$ 5.51 \$ 7.08 \$ 8.08 \$ 10.00$ $\$ 10.05 \$ 12.24 \$ 13.76 \$ 15.90 \$ 16.85 \$ 17.00 \$ 18.84 \$ 18.99$.

a. My payout will be:

6. Suppose I am in an auction with 20 players and 10 prizes. If I have a prize value of $\$ 14.75$ and I bid $\$ 8.00$ and my opponents' bids are (in increasing order): $\$ 0.54 \$ 1.03 \$ 2.91 \$ 3.75 \$ 3.80 \$ 4.40 \$ 4.83 \$ 5.51 \$ 6.08 \$ 7.10 \$ 7.75$ $\$ 10.35 \$ 13.34 \$ 13.89 \$ 14.90 \$ 17.85 \$ 17.90 \$ 18.84 \$ 19.99$.

a. My payout will be:

7. Suppose I have a prize value of $\$ 3.00$ and I bid $\$ 6.00$.

a. The highest my payout can be is: 
8. Finally, consider a more complicated situation: Here I have bid in 2 different auctions:

a. The first auction has 20 players and 10 prizes. If I have a prize value of $\$ 14.75$ and I bid $\$ 8.00$ and my opponents' bids are (in increasing order): $\$ 0.54 \$ 1.03 \$ 2.91 \$ 3.75 \$ 3.80 \$ 4.40 \$ 4.83 \$ 5.51 \$ 6.08 \$ 7.10$ $\$ 7.75 \$ 10.35 \$ 13.34 \$ 13.89 \$ 14.90 \$ 17.85 \$ 17.90 \$ 18.84 \$ 19.99$.

b. The second auction has 2 players and 1 prize. If I have a prize value of $\$ 14.75$ and I bid $\$ 10.00$ and my opponent bids $\$ 5.00$.

c. If you are offered the payout from the first auction plus $\$ 1.50$ your final payout will be:

d. If you are offered the payout from the second auction your final payout will be:

e. Lastly, if I offer you the payout from the outcome of the first auction plus $\$ 1.50$ or the payout from the second auction you are deciding between what two numbers? $\&$ 


\section{Auction Round Introduction}

Prior to the auction round, we posted an introduction with instructions:

Welcome to the auction round! In this round you will participate in 2 different auctions. The size of your prize has been randomly determined. We call it your "Prize Value" and you can see it below. This is the amount of money that you will receive if you win one of the prizes.

In each auction, you will compete with other participants for prizes by bidding a certain amount of money. You will be required to pay this bid regardless of the outcome of the auction. Even if you fail to win one of the prizes, you must pay your bid.

If there are more bids below your bid than above it, then you have a Winning Bid and will receive one of the prizes. That is, you will receive your Prize Value given below.

If your bid is not a Winning Bid, then you will simply lose the amount that you bid in the auction.

On the next 2 pages you will enter bids for both auctions. After all of the participants submit bids for both of the auctions, you will be told the outcomes of the auctions. You will not know the outcomes of the auctions until you have finished both auctions.

\section{Your Prize Value \$XX.XX}

\section{Auction Round}

Each screen of the auction round was identical, reminding the subject of instructions and important valuations:

\section{This is the $N$-Person Auction}

Remember: 
- You must pay your bid regardless of the outcome.

- You will win your Prize Value if your bid is higher than $\frac{N}{2}$ opponents' bids.

- One auction will be selected randomly to be the Auction That Counts, so treat each auction as if it is the Auction That Counts.

On this page you have been randomly assigned to an auction with $N-1$ other participants and yourself. You are competing to win one of $\frac{N}{2}$ prizes.

- Number of participants: $\mathbf{N}$

- Number of prizes: $\frac{N}{2}$

\section{Your Prize Value \$XX.XX}

Please enter your bid here:

\section{Auction Results}

After the subjects all bid in both auctions, we posted all results on one page:

- Your Prize Value was: \$XX.XX

- Your bid in the 2-Person Auction was: \$XX.XX

- In the 2-Person Auction you were in group G and you (Won/Lost)

- Your Payout from the 2-Person Auction: \$XX.XX

[List all 20 bids in all 10 auctions with winning bids paired with losing bids. The subject's bid is bold.]

- Your bid in the 20-Person Auction was: \$XX.XX

- In the 20-Person Auction you (Won/Lost)

- Your Payout from the 20-Person Auction: \$XX.XX 
[List all 20 bids in the auction with winning bids in the top row and losing bids in the bottom row. The subject's bid is bold.]

\section{Risk Aversion Elicitation}

There are three different risk preference elicitation tasks in the style of Andreoni and Harbaugh (2010).

Remember:

- The computer will choose 1 of the 3 pages of lotteries to determine your payment.

- You will be paid according to the outcome of the lottery you selected.

Please decide which option you prefer the most. Indicate your preference by filling in the one button next to your most preferred option:

- Win $\$ X_{1}$ with chance $C_{1}$ in 100

- Win $\$ X_{10}$ with chance $C_{10}$ in 100 


\section{A5: Bids by Auction and Session}

Bids in the 2-Person Auction in Session 1

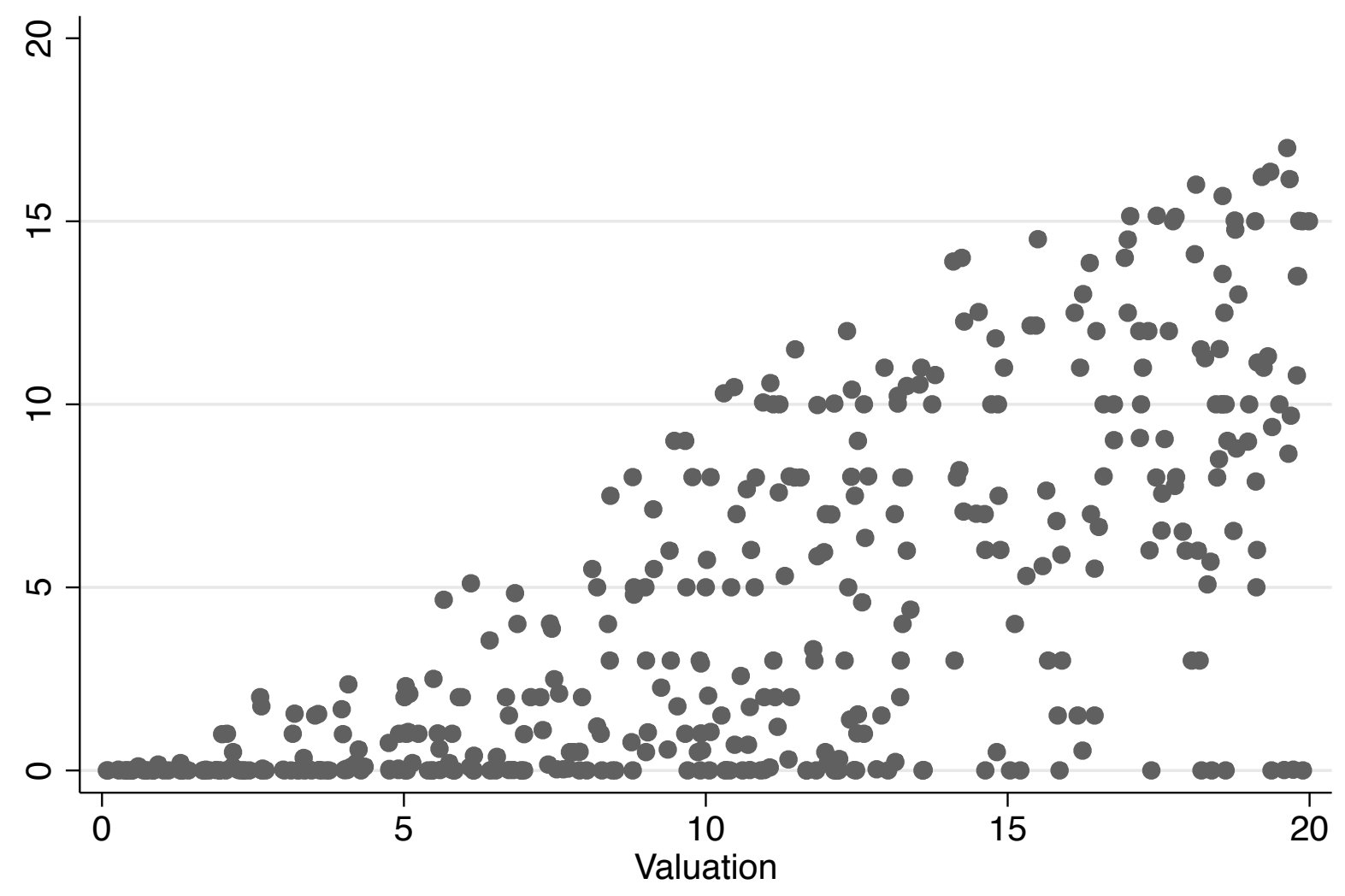


Bids in the 20-Person Auction in Session 1

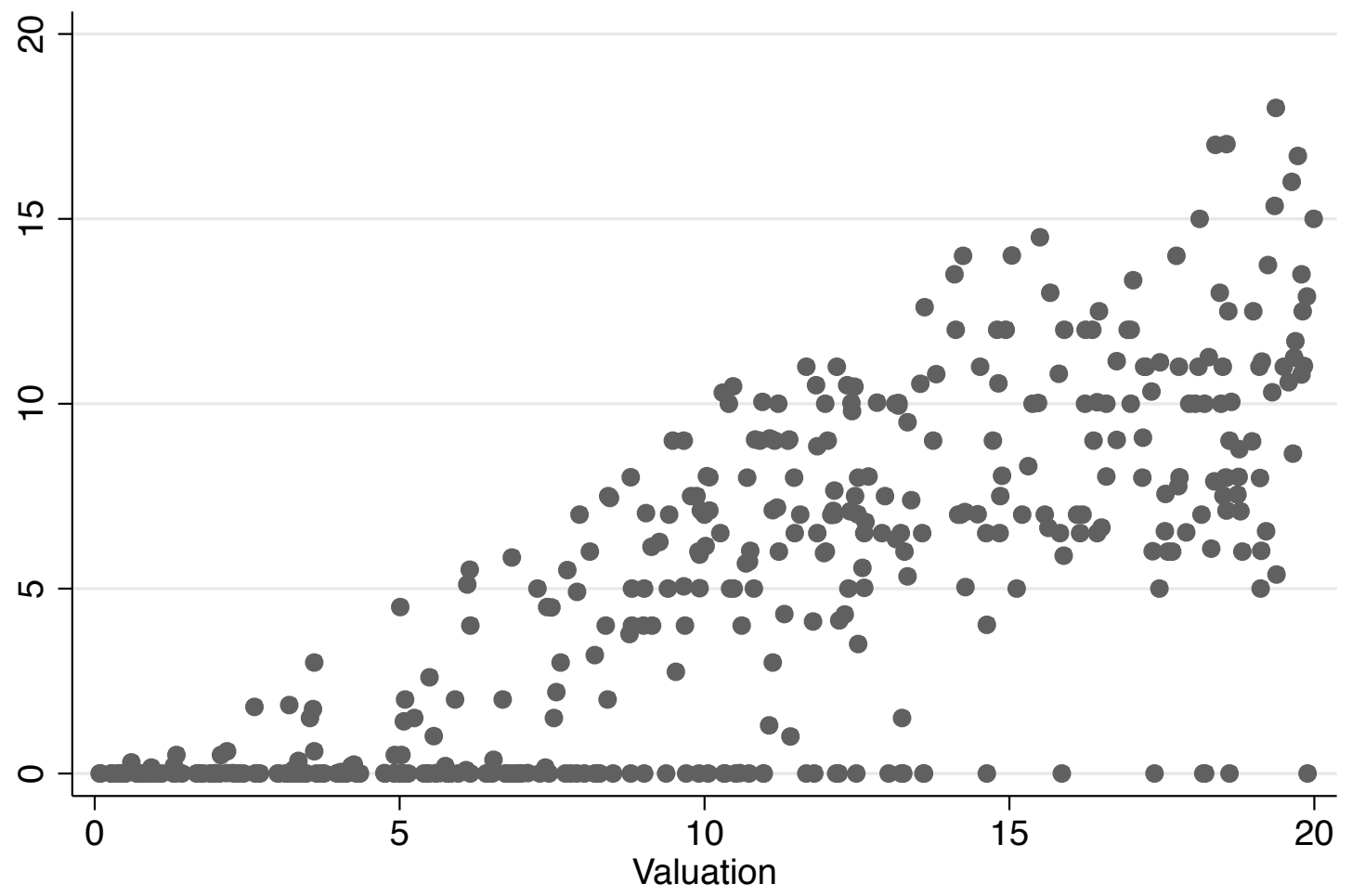

Bids in the 2-Person Auction in Session 2

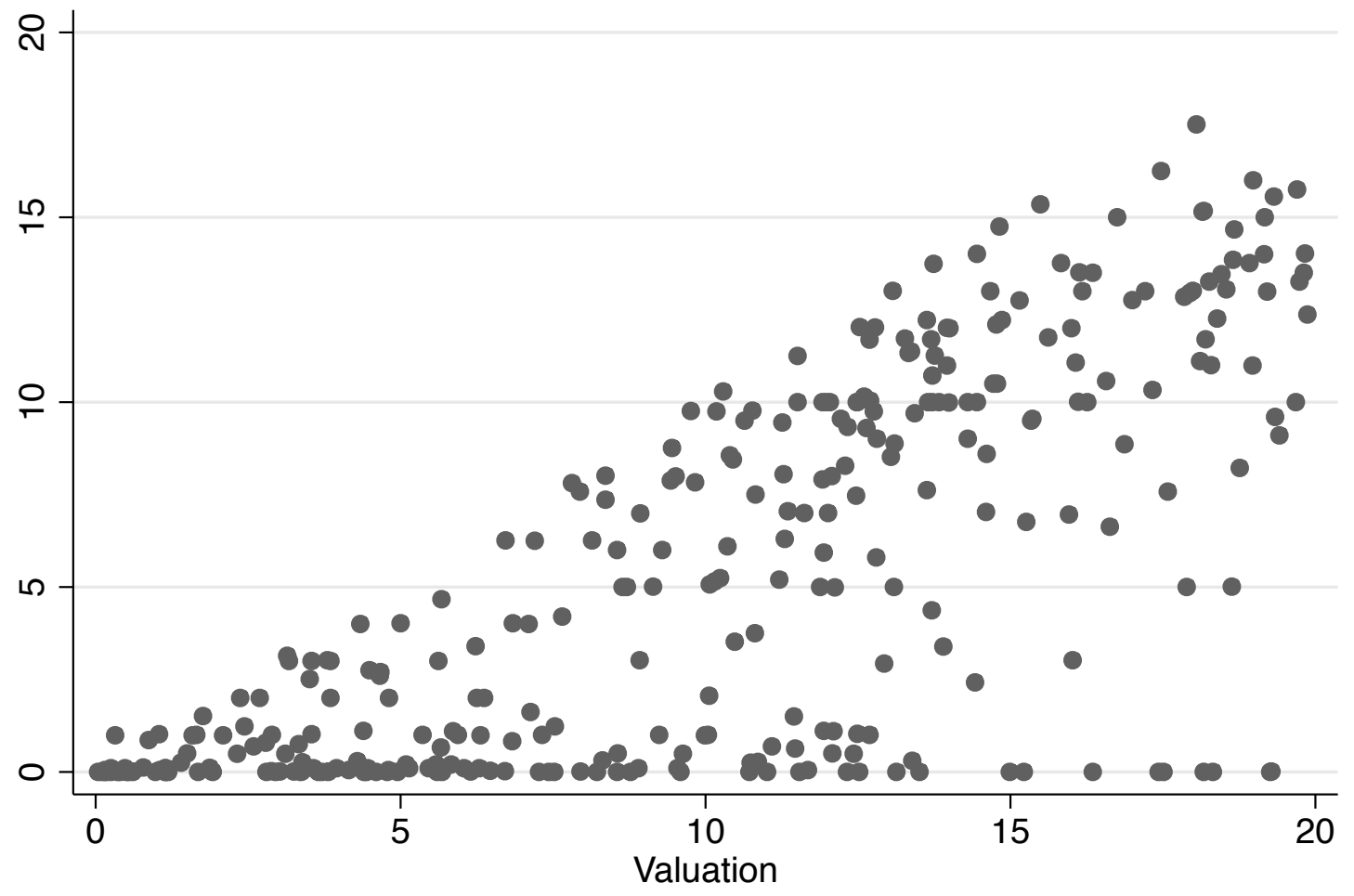


Bids in the 20-Person Auction in Session 2

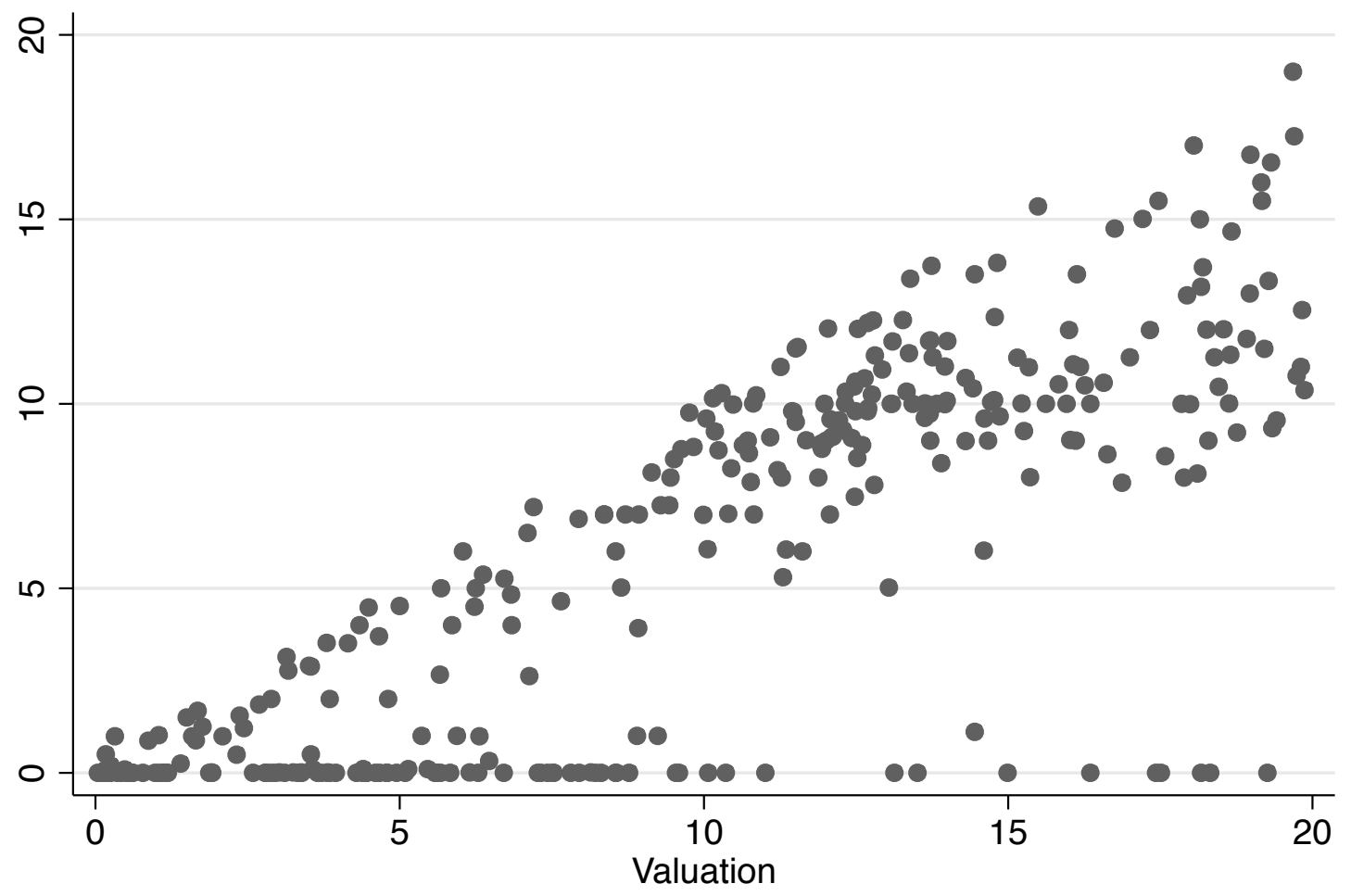

Bids in the 2-Person Auction in Session 3

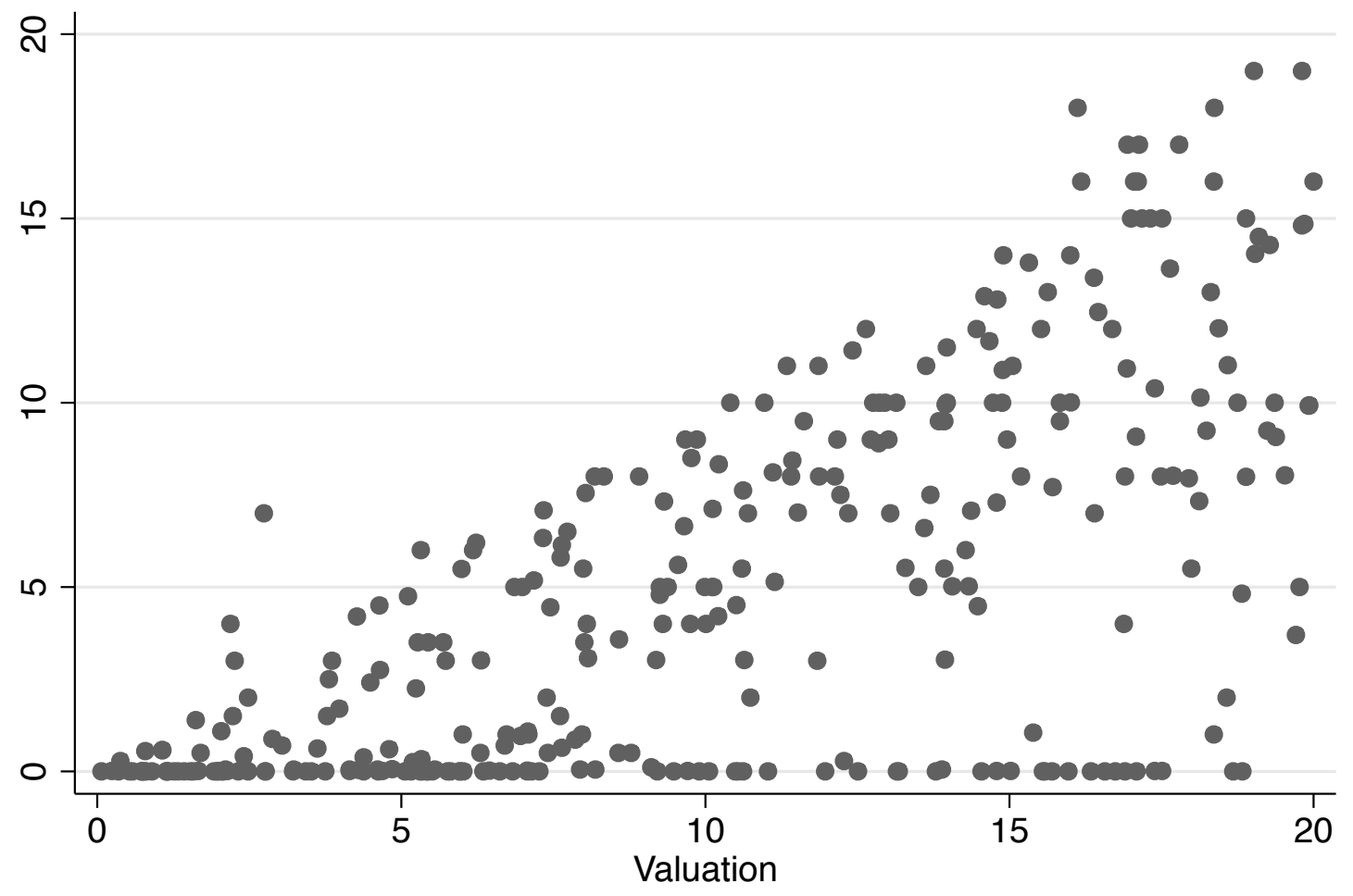


Bids in the 20-Person Auction in Session 3

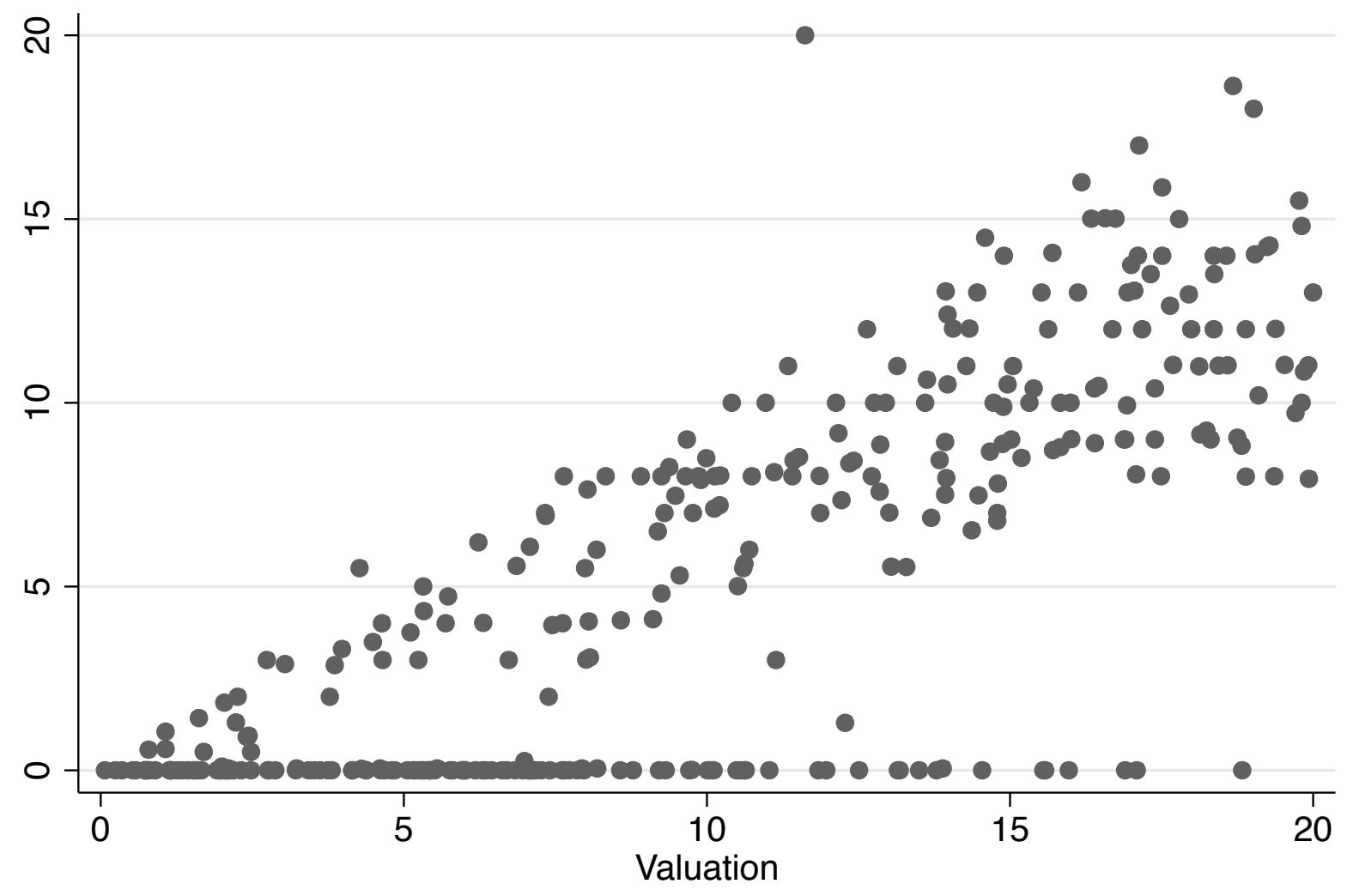

